\title{
OZONE PROTECTION IN PLANTS \\ THE POTENTIAL USE OF \\ CHEMICAL PROTECTANTS TO MEASURE ATMOSPHERIC \\ OXIDANT DAMAGE IN ALBERTA CROPS
}

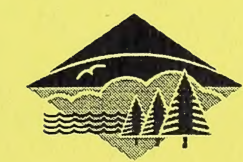


Digitized by the Internet Archive in 2016

https://archive.org/details/ozoneprotectioni00arch 


\section{OZONE PROTECTION IN PLANTS}

\section{THE POTENTIAL USE OF CHEMICAL PROTECTANTS TO MEASURE ATMOSPHERIC OXIDANT DAMAGE IN ALBERTA CROPS}

by:

Daniel J. Archambault, Jan J. Slaski and Xiaomei Li

Environmental Technologies

Alberta Research Council

Vegreville, Alberta

\section{Prepared for}

Science and Technology Branch

Environmental Sciences Division

Alberta Environment

9820 - 106 Street

Edmonton, Alberta

T5K 2J6 
Pub. No. T/557

ISBN: $\quad 0-7785-1226-6$ (Printed Version)

ISBN: $0-7785-1227-4$ (On-Line Version)

Web Site: http://uww.gov.ab.ca/env/resrched.html

Although prepared with funding from Alberta Environment (AENV), the contents of this report/document do not necessarily reflect the views or policies of AENV, nor does mention of trade names or commercial products constitute endorsement or recommendation for use.

Any questions on this document may be directed to:

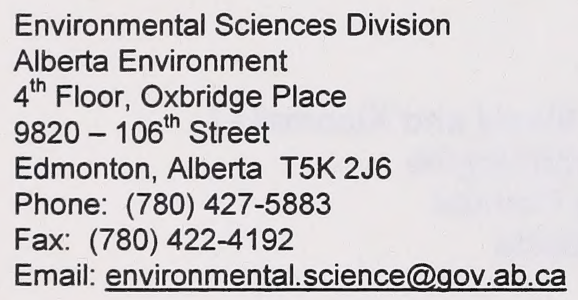

Additional copies of this document may be obtained by contacting:

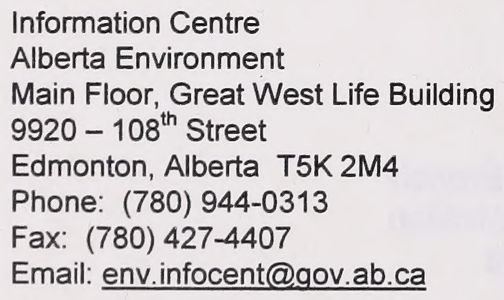

This report may be cited as:

Archambault, D.J., Slaski, J.J., Li, X., 2000. Ozone protection in plants. The potential use of chemical protectants to measure oxidant damage in Alberta crops. ISBN 0-7785-1226-6. Report prepared for the Air Research Users Group, Alberta Environment, Edmonton, Alberta. 


\section{FOREWORD}

Ozone in air at ground-level originates from two sources. Stratospheric ozone (the protective ozone that helps screen the Earth's surface from UV light) may be brought to ground-level as a result of atmospheric turbulence. Ozone at ground-level is also formed as a consequence of reactions among substances naturally present in the atmosphere, and among substances that are produced by human activity. A powerful oxidant, ozone has the potential to harm natural, agricultural, and horticultural plant species. Research into the effects of ozone has been extensive, but despite this effort, there is still a great deal of uncertainty regarding the levels of ozone that are harmful to plants.

Much of the scientific research effort to date has concentrated on examining the effects of ozone that has been added to the air, either in growth chambers, field chambers, or through field systems that do not use enclosures. While these efforts have provided important information on the concentration of ozone, and the duration of ozone exposure that may affect plant growth, the artificial nature of these experimental conditions has limited the applicability of much of the information.

Adding ozone to air and evaluating the effects on plants is one way to approach this problem, and this has been the approach most commonly used. A lesser used method is to remove ozone from the air and observe changes in plant growth. A third way to approach this problem is to treat plants with a substance that "protects" the plant from ozone exposure. Several chemical substances have been found to have the properties of a "protectant" - they cause the plant to become insensitive to ozone, or they react with ozone before the ozone can react with plant tissues. Use of these substances has recently expanded the ability of researchers to investigate the mechanisms by which ozone in air may affect plant growth.

The Air Research Users Group of Alberta Environment has commissioned this report in order to provide a review and interpretation of the scientific literature that describes the use and effects of chemical ozone protectants. The authors of this report were asked to determine if there was sufficient information available on these substances to warrant a field evaluation of their use. This was done as part of Alberta Environment's efforts to determine if ozone has the potential to cause negative (or positive) effects on plants in the province, with a focus on agricultural crops. The results of this review and interpretation will assist Alberta Environment in making a decision on whether or not to conduct a field investigation into the potential use of chemical ozone protectants as part of an evaluation of the possible effects of ozone on Alberta crops.

Kenneth R. Foster, Ph.D., P.Biol. Project Coordinator, Air Research Users Group

Science and Technology Branch

Environmental Sciences Division

Alberta Environment 


\section{EXECUTIVE SUMMARY}

Ozone is an important phytotoxic gaseous pollutant in Canada, the USA and many other industrialized countries. Crop injury and loss induced by elevated ground level ozone has been reported in these countries leading to a widespread effort at the protection of plants using various means. Protection may be achieved by coating the leaf surface and providing physical and/or chemical protection, through the alteration of gas exchange or through the alteration of plant metabolism.

Although several reviews assessed the usefulness of protectants against ozone damage a more comprehensive review of plant protectants against ozone is needed in order to develop a tool to quantify the effects of elevated ground level ozone on Alberta crops. Our intent was to conduct a literature search and to provide a comprehensive review of this subject, and an interpretation of the literature, including detailed recommendations regarding the use of protectants for the evaluation of the potential for ozone effects on Alberta crops.

The earliest report of plant protection from ozone showed that pinto bean leaves could be protected from ozone injury by spraying them with aqueous suspensions of manganese (maneb) or zinc ethylenebis dithiocarbamate (zineb) prior to fumigation. The use of chemicals that cause stomatal closure such as phenylmercuric acetate and monoethyl esters of decenylsuccinic acid can protect plants from entry of ozone into leaves. Freebairn (1960) and Freebairn and Taylor (1960) were the first to modify plant metabolism to protect plants from ozone by applying vitamin $\mathrm{C}$ as a spray. Since then, a large number of chemicals used singly and in combination have been evaluated for their abilities to protect plants from ozone injury.

Ozone protectants can be grouped as pesticides, including fungicides, insecticides, and herbicides, plant growth regulators, dusts and mechanical barriers, and antioxidants, such as ethylene diurea (EDU). Several studies suggest that the application of these chemical protectants against ozone might be a reliable means by which to assess ozone effects on crops under field conditions. While many chemicals have been shown to convey partial or total protection against ozone injury, many are ineffective and have unacceptable side-effects rendering them of little value for the purpose of assessment of crop effects in the field. This is true of some of the most promising antiozonants. For example, even though the fungicide benomyl has been found to effectively control ozone injury in a number of plants, it would be impossible to separate the fungicidal benefits from its antiozonant properties in the field.

In the late 1980's and throughout the 1990's the focus has been on the evaluation and understanding of EDU as a protectant from ozone injury. Researchers reported that EDU reduced and/or delayed the appearance of ozone damage to developing foliage and delayed plant senescence and leaf abscission. These findings showed promise for the use of EDU as a general protectant against ozone damage but in order to be useful as a tool for the determination of crop losses due to ozone exposure, it was also necessary to verify whether EDU caused side-effects in the absence of ozone.

Since then, studies have been conducted to establish optimized protocols for the use of EDU in programs aiming at the quantification of the effects of ozone on vegetation and to understand the 
process by which EDU conveys resistance to ozone. From the extensive literature on the subject, it is apparent that the effects of EDU are species- and sometimes cultivar-specific, that the dose, frequency and mode of application are critical and that one must take into consideration the length and frequency of ozone exposure as well as environmental conditions in developing a protocol for EDU use.

Dose response experiments will not only allow for the determination of the optimal dosage of EDU to convey resistance to ozone but will also allow for the determination of possible sideeffects of EDU by application of EDU to plants grown in the absence of ozone in parallel to application to plants being exposed to ozone. In the first studies by Carnahan et al. (1978) in which plants were exposed to acute ozone treatments, various dosages of EDU were tested. Since then, while proper dose response protocols have been followed in many experiments, several studies have been conducted using EDU dosages that were extrapolated from previous experiments. Some of these extrapolations were done from acute to chronic ozone studies and have led to under- or over-dosages of EDU. The misuse of the EDU method has led to ineffective protection by EDU and EDU-induced toxicity resulting in reduced yields.

Applications of EDU as a soil drench and as a foliar spray have been successful in conveying resistance to ozone injury in plants but the possibility of soil accumulation of EDU and the subsequent possibility of toxicity argue for the use of foliar applications. Perhaps the greatest factors determining the appropriate mode of application are practical issues. On the large scale and in the field, it is perhaps not feasible to apply soil drenches at all stages of plant development, especially in crops that are not grown in rows such as hay and broadcasted cereal crops where it would not be possible to apply EDU to the soil without simultaneous application onto above-ground organs. The application of EDU as a soil drench at field scale would also require large volumes of solution while surface applications would depend on precipitation to carry the chemical to the plant roots. Foliar application appears to be the most practical especially for large-scale field studies.

We conclude that EDU is specific in the suppression of ozone injury in a wide variety of plant species. Studies conducted to date have shown that EDU has few side-effects and is effective on almost all plants studied. If appropriate exposure/response and toxicological studies are conducted with EDU and ozone, it should be possible to use EDU for assessing crop effects in the field. Therefore we recommend that the EDU method be adopted for studies aimed at the assessment of crop effects under field conditions in Alberta. EDU at a concentration of $250-$ $500 \mathrm{ppm}$ should be applied to the foliage to runoff every 7 to 10 days throughout the vegetation period. This should allow for the partial or total mitigation of ozone effects in chronic exposures at concentrations of up to $80 \mathrm{ppb}$. For the preliminary determination of the potential use of EDU in assessing effects of ozone on crops of Alberta, we recommend that studies be conducted at sites where ozone levels are greatest, perhaps Fort Saskatchewan or east Edmonton, with an ozone control site established near Vegreville where ozone levels are very low. Information on the relative sensitivity of common Alberta crops is lacking, making it difficult to determine which species should be used in these studies. We recommend that at least two species be studied. Based on their relative importance, we recommend that barley (Hordeum vulgare) and canola (Brassica napus - the most common species of canola) be used. 


\section{ACKNOWLEDGEMENTS}

This project was supported by funds from Alberta Environment. The authors thank Dr. Kenneth Foster for his numerous comments and suggestions during the preparation of this report. 


\section{TABLE OF CONTENTS}

Foreword

Executive Summary ..............................................................................................................ii

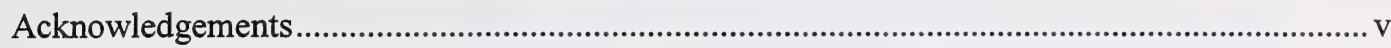

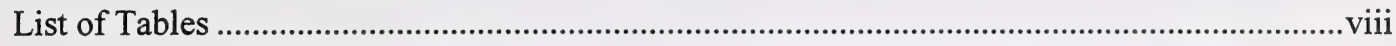

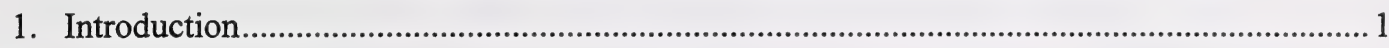

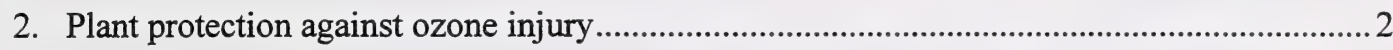

2.1. The use of pesticides as ozone protectants ....................................................................

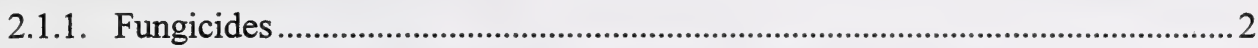

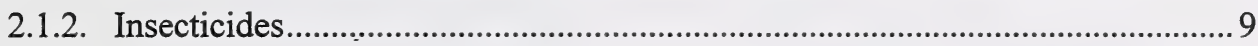

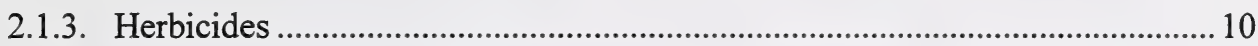

2.2. The use of growth regulators, dusts and mechanical barriers and other chemicals as ozone protectants ............................................................................................................ 10

2.3. The use of antioxidants as ozone protectants............................................................... 13

2.4. The use of ethylene diurea (EDU) as an ozone protectant......................................... 15

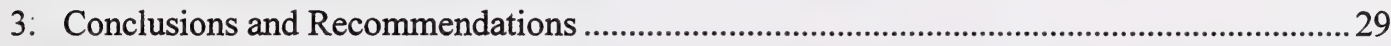

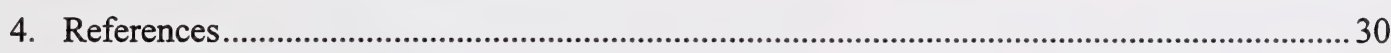




\section{LIST OF TABLES}

Table 1. Pesticides used to protect plants from ozone injury; plant species studied and references.

Table 2. Benzimidazole, carboxin and their derivatives used to protect plants from ozone injury; plant species studied and references.

Table 3. Various chemicals used to protect plants from ozone injury; plant species studied and references.

Table 4. Antioxidants used to protect plants from ozone injury; plant species studied and references.

Table 5. Dosage, mode and number of applications, ozone treatments, plant species and references for studies that have made use of the antioxidant EDU to protect plants from ozone injury. 


\section{INTRODUCTION}

Deleterious effects of atmospheric oxidants have been recognized since the first observations of damage to ornamental plants and crops in California in the early 1940s. While a number of oxidants have been found to be toxic to plants, few are found in sufficient quantities in the Canadian environment to cause noticeable effects on vegetation. Ozone is recognized as the most prevalent photochemical oxidant and its effects on vegetation have been extensively studied.

Studies of the potential for protection of vegetation from ozone injury using chemical applications have been conducted over the last four decades. Rich (1964) reviewed some aspects of protection with emphasis on early attempts using fungicides and inert surface-active materials. In 1974, Ormrod and Adedipe published a paper on "Protecting Horticultural Plants from Atmospheric Pollutants: A Review" in HortScience. The article contained a short historicallyoriented section on chemical protectants. Ormrod and Adedipe divided chemical protectants into fungicides, antioxidants and growth regulators. In 1977, the Committee on Medical and Biologic Effects of Environmental Pollutants published a list of chemicals used in protecting plants against oxidant injury in a book chapter "Plants and Microorganisms" in "Ozone and Other Photochemical Oxidants". The list contains chemicals used against ozone and general oxidant injury and suggests a research focus on tobacco, bean and ornamentals such as poinsettia and petunia.

Manning and Krupa (1992) presented a list of examples of chemicals used to protect plants from ozone injury with references spanning from 1960 to 1991 . The most recent work has been on EDU (ethylene diurea N-[2-(2-oxo-1-imidazolidinyl)ethyl]-N'-phenylurea) and EDU as a protectant against ozone damage has shown the most promise. The review by Pandey and Agrawal (1993) echoed this opinion and recent discussions on the use of ozone protectants have made little reference to chemicals other than EDU (Musselman and Hale 1997). These authors suggest that "there appears to be no current research being conducted on the usefulness of fungicides and other antioxidants for $\mathrm{O}_{3}$ injury to vegetation". A second observation that can be made from the present review is that many researchers have focused their attention on the use of a number of chemicals in protecting tobacco from injury in southern Ontario, Canada (Gayed 1983; Bisessar and Palmer 1984; Walker 1961,1966,1967), in the northeastern United States (Bertinuson et al. 1961; Silber 1964; Taylor and Rich 1961,1962,1974; Taylor 1970; Miller and Taylor 1970; Miller et al. 1976; Reinhart and Spurr 1972; Sung and Moore 1979; Reilly and Moore 1982; Moyer and Smith 1995; Godzik and Manning 1998), Japan (Fukuda et al. 1975a,b; Toshikiyo et al. 1976; Koiwai 1977; Koiwai and Hiroshi 1975; Koiwai and Kisaki 1976) and Italy (Lorenzini et al. 1987).

The purpose of this report is to develop recommendations for the use of ozone protectants in Alberta in order to evaluate the effects of ozone on crops. The recommendations will be based upon a review of the literature. 


\section{PLANT PROTECTION AGAINST OZONE INJURY}

The literature on the effects of ozone on agricultural crops of Canada has been recently reviewed (Pearson and Percy, 1997) and hence, the effects of ozone on crops will not be reviewed in detail in this document. Briefly, ozone diffuses through stomatal pores at the leaf surface, dissolves and decomposes rapidly to produce toxic oxygen species. Visual symptoms of ozone injury are primarily observed on leaves causing bronzing, necrosis and desiccation and in advanced stages results in rapid and premature senescence and leaf drop. Retardation of growth and severe (up to $45 \%$ ) loss of yields in crop plants may occur (Pearson and Percy, 1997).

Research into the potential protection of plants from oxidant damage has included a number of approaches (Tables $1-5$ ). Protection may be achieved by coating the leaf surface and providing physical and/or chemical protection, through the alteration of gas exchange or through the alteration of plant metabolism.

The earliest report of plant protection from ozone is by Middleton et al. (1953) who showed that pinto bean leaves could be protected from ozone injury by spraying them with aqueous suspensions of manganese (maneb) or zinc ethylenebis dithiocarbamate (zineb) prior to fumigation. Rich (1964) and Seidman et al. (1965) reported on the use of chemicals that cause stomatal closure such as phenylmercuric acetate and monoethyl esters of decenylsuccinic acid to protect plants from entry of ozone into leaves. Freebairn (1960) and Freebairn and Taylor (1960) were the first to use metabolic effectors to protect plants from ozone by applying vitamin $\mathrm{C}$ as a spray (Table 4). Since then, a large number of chemicals used singly and in combination have been evaluated for their abilities to protect plants from ozone injury. In the late 1980's and throughout the 1990's the focus has been on the evaluation and understanding of EDU as a protectant from ozone injury. While caveats on the use of EDU for this purpose have arisen, EDU is currently widely used (Table 5) and is part of the research conducted within the framework of the International Cooperative Program on the effects of air pollutants on crops and non-woody plants (ICP-Crops) established as part of the United Nations/Economic Commission for Europe (UN-ECE) working group (for example: Schenone et al. 1995; Tonneijck and Van Dijk 1996).

\subsection{The use of pesticides as ozone protectants}

A number of studies have made use of pesticides such as fungicides, herbicides and insecticides to protect plants against ozone injury and a summary of those studies is provided in Tables 1 and 2.

\subsubsection{Fungicides}

Because of the extensive use of benzimidazole, carboxin and their derivatives we have elected to treat these in a separate section below. A report on the use of fungicides other than those mentioned above is given in the section entitled 'Various fungicides'. 

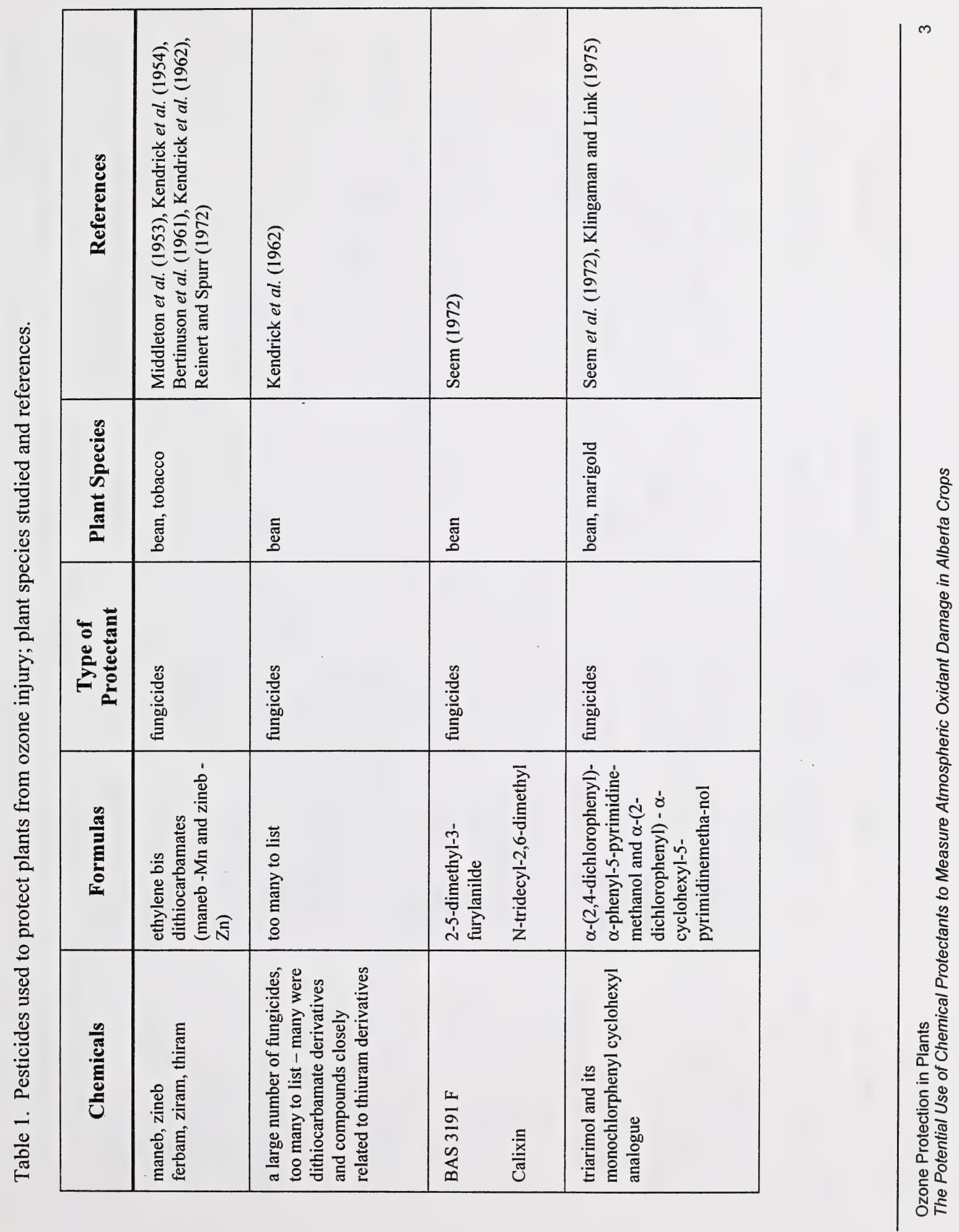


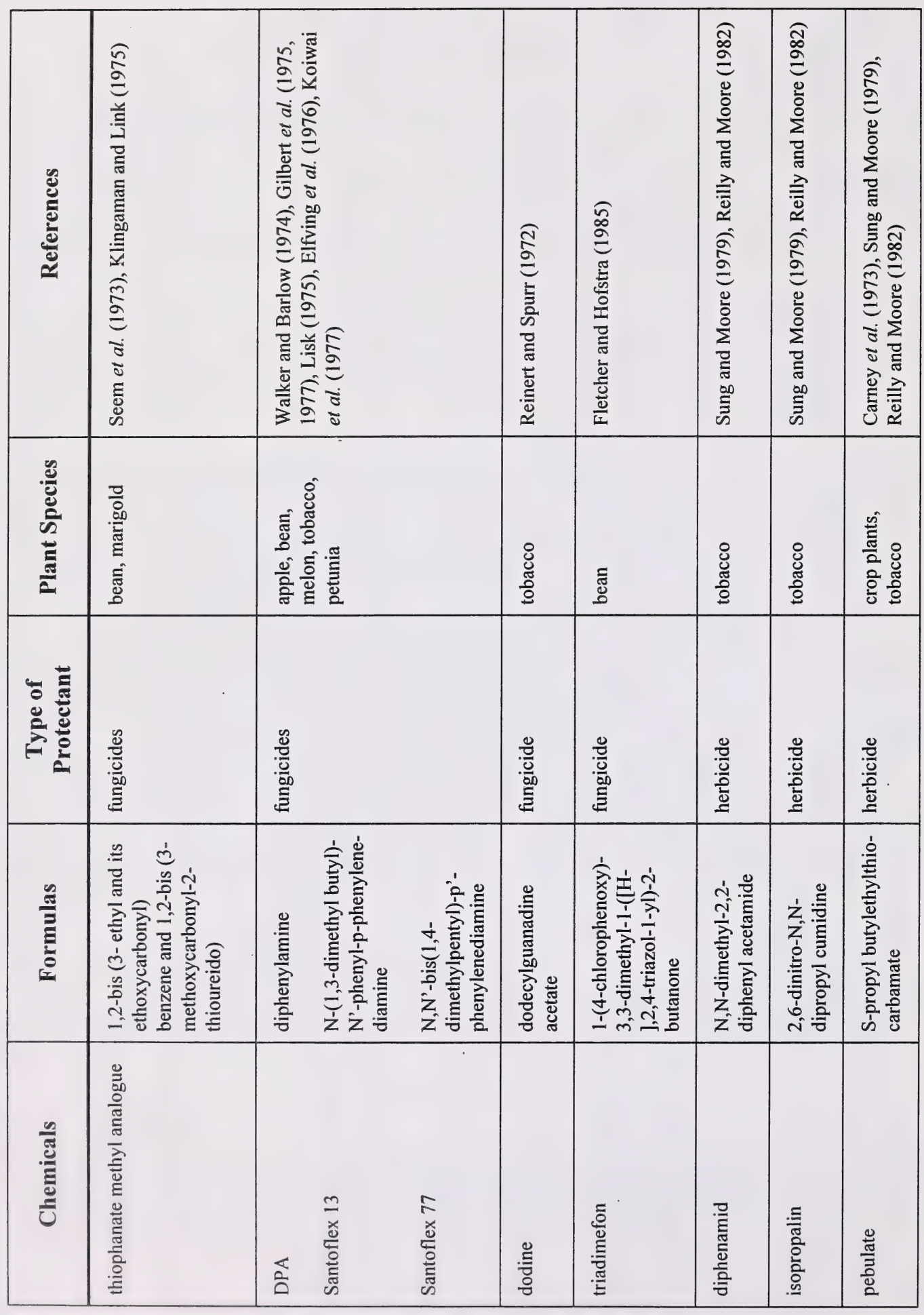




\begin{tabular}{|c|c|c|c|c|c|c|c|}
\hline 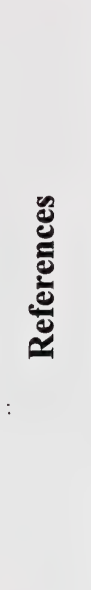 & 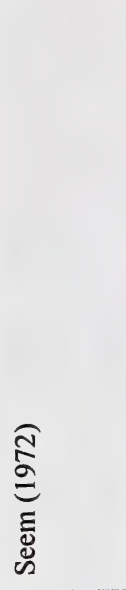 & 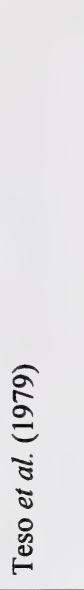 & 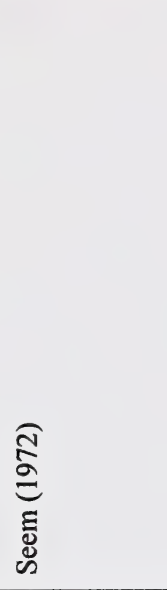 & & & 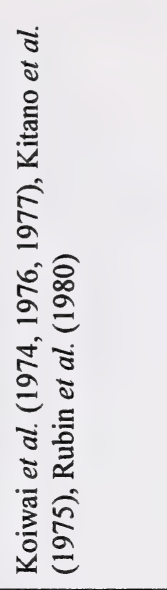 & 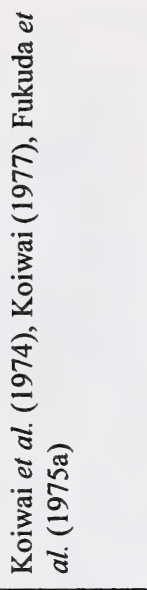 \\
\hline 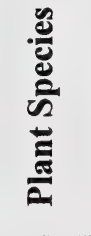 & 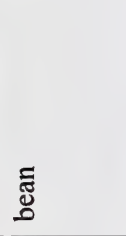 & ฐ్ & ฐ్ & & & 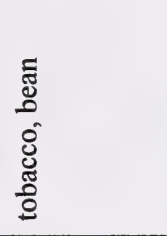 & 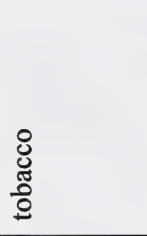 \\
\hline 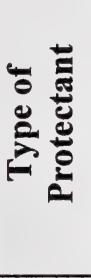 & 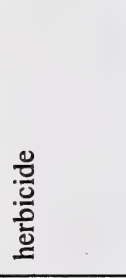 & 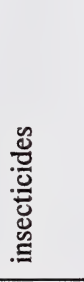 & 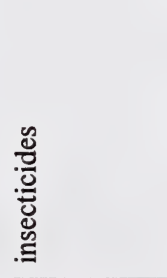 & & & 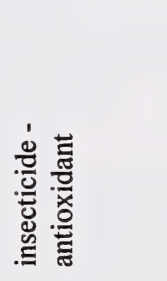 & 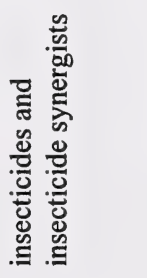 \\
\hline 兽 & 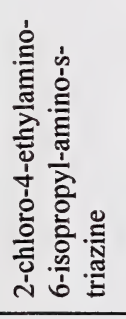 & 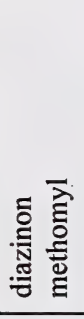 & 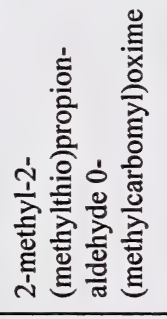 & 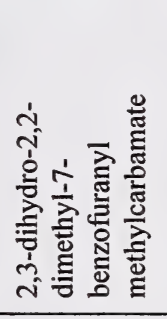 & 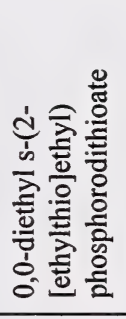 & 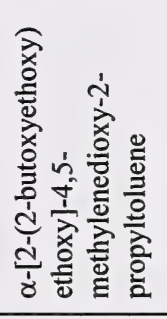 & 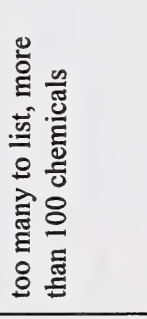 \\
\hline 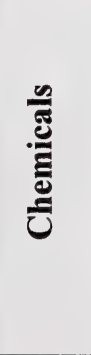 & 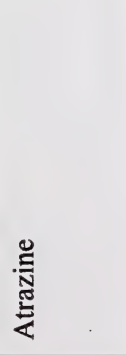 & 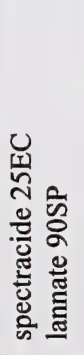 & $\begin{array}{l}\text { 䔍 } \\
\text { 总 } \\
\frac{\pi}{\pi}\end{array}$ & 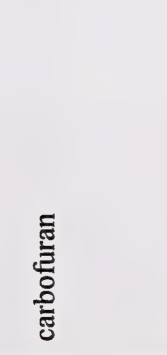 & 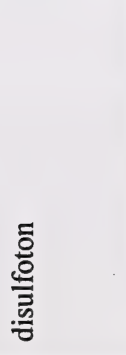 & 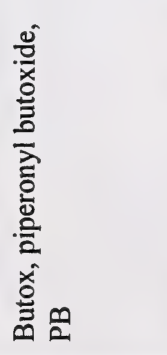 & 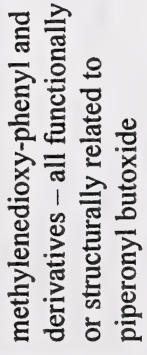 \\
\hline
\end{tabular}

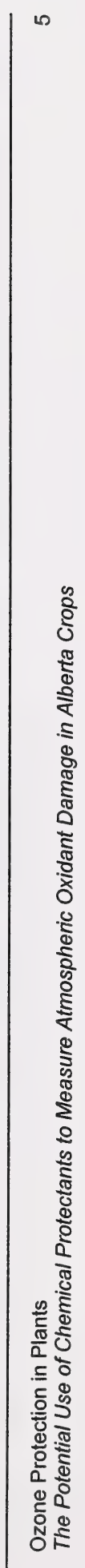




\begin{tabular}{|c|c|c|c|c|c|c|}
\hline 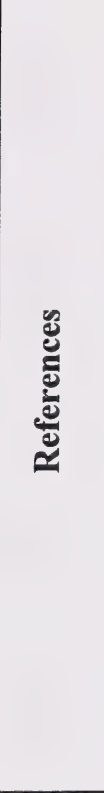 & 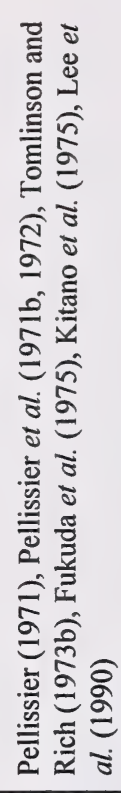 & 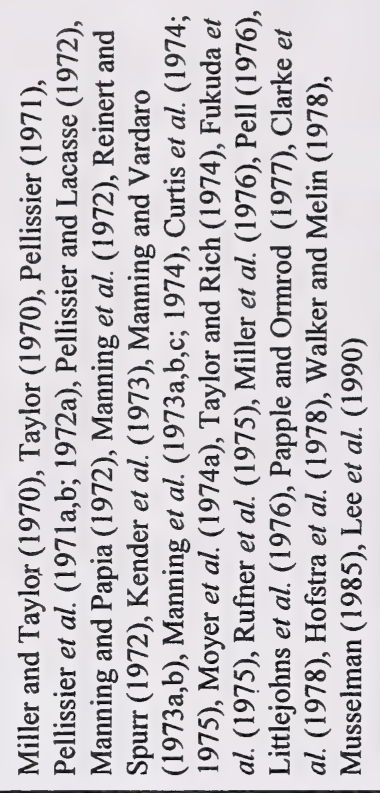 & 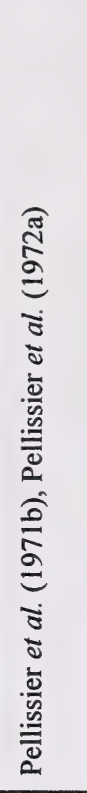 & 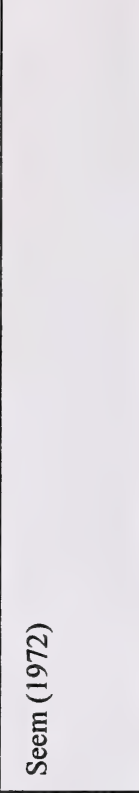 & 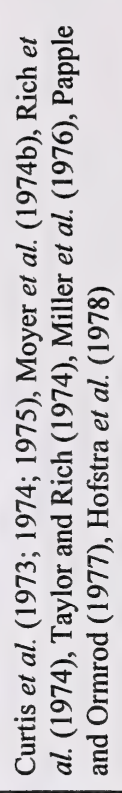 & 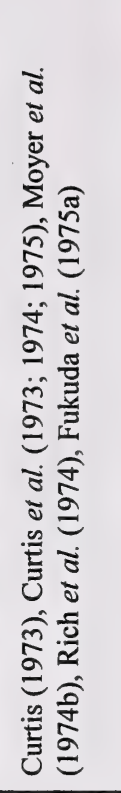 \\
\hline 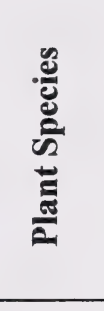 & 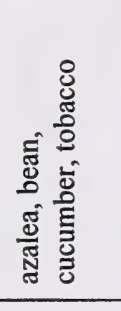 & 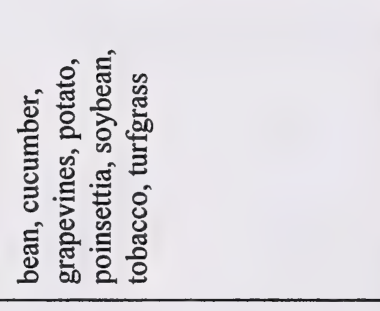 & 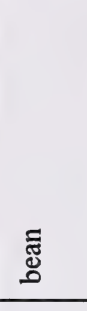 & త్ల్ & 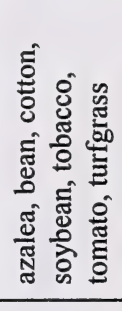 & 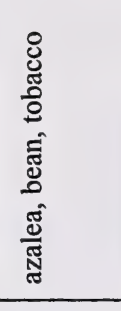 \\
\hline 竞 & 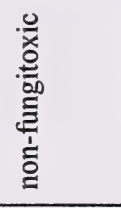 & 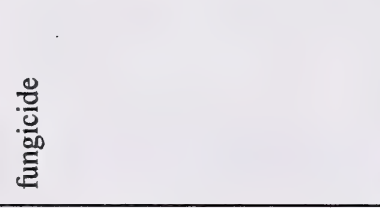 & 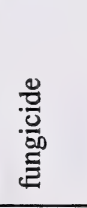 & 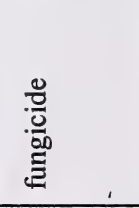 & 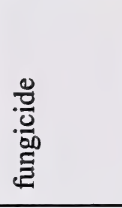 & 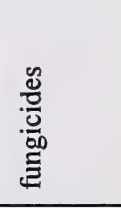 \\
\hline 产 & & 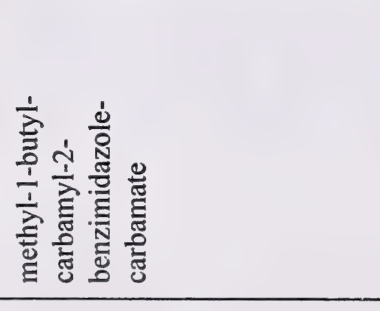 & 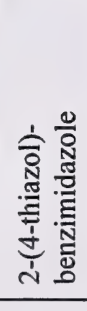 & 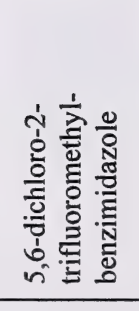 & 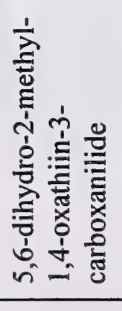 & 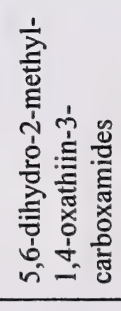 \\
\hline 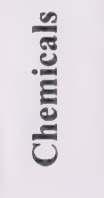 & 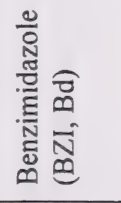 & 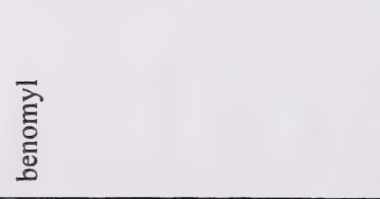 & 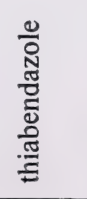 & 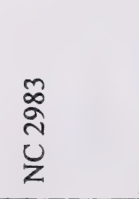 & 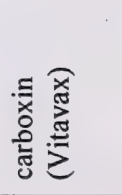 & 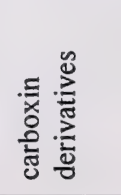 \\
\hline
\end{tabular}

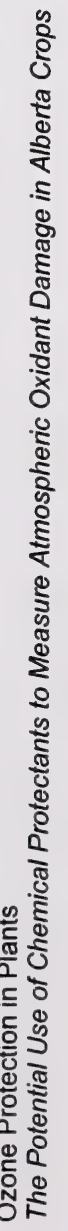




\section{Various fungicides}

Middleton et al. (1953) and Kendrick et al. (1954) were among the first to report on the protective qualities of specific sprays and dusts. They showed that plant injury caused by ozonated gasoline or hexene-1 could be prevented using sprays or dusts of zinc ethylene bis dithiocarbamate (zineb), manganese ethylene bis dithiocarbamate (maneb), tetramethylthiuram disulfide (thiram), or ferric dimethyl dithiocarbamate (ferbam). In these studies, they found that fungicides such as 2,3-dichloro-1,4-naphthoqinone (dichlone) or tetrachloro-p-benzoquinone (chloranil) did not protect bean plants. They later showed that the degree of protection was directly related to the concentration of the chemicals. In studies conducted in Connecticut between 1955 and 1959, Bertinuson et al. (19.61) also found that zineb could offer some degree of protection to shade-grown tobacco plants. Kendrick et al. (1962) later published results of extensive studies on the use of fungicides as well as antioxidants from the rubber industry as ozone protectants. Because the action of the protectants was localized and not systemic they suggested that the effect was that of deactivation of the oxidants upon application of the chemical protectant. They also found that the degree of protection was related to accumulated periods of exposure to toxicants. Seem (1972) reported on the potential of the herbicide atrazine, the fungicides BAS $3191 \mathrm{~F}$, calixin and NC 2983 and the insecticides aldicarb, carbofuran and disulfoton in protecting bean plants against ozone damage. They found that the systemic fungicide $\alpha$-2,4-dichlorophenyl- $\alpha$ phenyl-5-pyrimidinemethanol (triarimol) reduced ozone injury. Seem et al. (1973) also showed that thiophanate ethyl and its methyl analogue were highly effective in suppressing ozone injury in bean plants. Reinert and Spurr (1972) showed that while dodine and maneb did reduce ozone injury in tobacco leaves, they were not as effective as benomyl.

Walker (1966) found that the application of diphenylamine (DPA) as a foliar spray was highly effective in protecting flue-cured tobacco from weather fleck. Dust and liquid applications of DPA to apple and dust applications of DPA to bean, muskmelon and petunia were shown to provide protection against ozone (Gilbert et al. 1975). This fungicide was also used to quantify the effects of ambient oxidants on plants during monitoring of air quality in Georgia, U.S.A. (Walker and Barlow 1974). Lisk (1975) found that foliar application of DPA at 1000ppm (for apple) and $1 \%$ (for bean, melon, petunia and tobacco) reduced ozone damage by $50 \%$ or more. A combination of DPA and the antitranspirant Wilt Pruf proved to be even more effective in protecting apple foliage from ozone damage than either used singly (Elfving et al. 1976). The DPA derivative Santoflex 13, an ozone protectant used to protect rubber products, has been shown to offer significant protection to tobacco, muskmelon and bean from ozone injury while another similar derivative Santoflex 77 did not (Gilbert et al. 1977).

\section{Benzimidazole, carboxin and their derivatives as ozone protectants}

Benzimidazole, carboxin and their derivatives, all of which are fungicides with the exception of benzimidazole, have been tested extensively for their abilities in reducing ozone effects in plants including bean, soybean, cucumber, potato, tobacco, grapevines, turfgrass, poinsettia, azalea and cotton. A summary of a number of such studies is given in Table 2. Like research on other 
pesticides described above, most studies on the potential benefits of benzimidazole, carboxin and their derivatives date from the 1970's and later studies are uncommon.

Based on the finding that benzimidazole and benomyl supplied at benzimidazole-equivalent dosages equally protected pinto beans from ozone injury, Pellissier et al. (1972a) concluded that it was the benzimidazole moiety that was responsible for the antiozonant effect. In 1973, Tomlinson and Rich (1973a) reported on the protection of chlorophyll and free sterols in membranes of bean plants exposed to ozone. Following the evaluation of an extensive number of chemicals as protectants of tobacco against ozone injury, Fukuda et al. (1975a,b) and Kitano et al. (1975) found that benzimidazole was among the most effective chemicals used with benzimidazole and some of its derivatives being surpassed only by piperonyl butoxide. Like Tomlinson and Rich (1973), Fukuda et al. found that benzimidazole protected chlorophyll from damage by ozone. At that time and in subsequent years, a number of the benzimidazole derivatives were studied.

The fungicide benomyl is by far the most studied benzimidazole derivative as evidenced by the list shown in Table 2. The vast majority of studies using benomyl have focused on its application to tobacco and bean. From 1972 to 1974, Manning and co-workers published a series of papers on the use of benomyl as an ozone protectant in beans and poinsettia. Manning et al. (1972) published results of experiments in which they looked at the effects of benomyl application as a soil amendment on growth and nodulation in pinto beans. They found that while benomyl could protect plants temporarily from ozone, plants exposed to benomyl showed either equal or decreased growth and nodulation compared to controls. Manning et al. (1973a) also used soil amendments of benomyl to study the response of pinto bean to repeated exposures to low levels of ozone. They found that benomyl amendments were not effective in overcoming the long-term deleterious effects of ozone and that benomyl caused dose-dependent toxicity symptoms. In 1973, Manning et al. (1973b) applied benomyl as a foliar spray to bean plants grown in field plots. They found that benomyl provided $70-80 \%$ suppression of oxidant injury. In the same year, Manning and Vardaro (1973) showed that benomyl supplied as a soil drench could significantly reduce the incidence of chronic ozone injury in two cultivars of poinsettia. Manning et al. (1974) found that benomyl applied as a foliar spray suppressed ozone injury by up to $80 \%$ in two sensitive cultivars of bean while no beneficial effects were found when benomyl was applied to an ozone resistant cultivar that suffered only minor visible injury. They also found that benomyl only caused yield recoveries in the most ozone-sensitive cultivars.

While in the early 1970 's, the discovery that benomyl could protect plants against ozone injury opened a new area of investigation, the discovery that carboxin had similar beneficial effects rapidly led to side-by-side comparisons of the two chemicals. Manning and Vardaro (1973b) showed that while benomyl sprays protected bean plants from ozone injury, carboxin applied over seed at planting provided complete suppression of oxidant injury for up to 40 days. However, Taylor and Rich (1974) found that while both benomyl and carboxin could reduce the amount of visible injury, applications of carboxin to the soil supporting tobacco plants could lead to toxicity while benomyl, applied at greater dosages, had mostly beneficial effects. Rich et al . (1974) had also found that when carboxin was applied to soil, the dosage necessary to protect plants from ozone injury was close to the phytotoxic dose. They observed that soil treatments 
that were sufficient to protect plants from ozone caused the yellowing of leaf margins and stunting. Curtis et al. (1974) reported that foliar sprays of carboxin and its sulfoxide analogue (F-831) were more effective in preventing yield loss in white beans than was benomyl. After Miller and Taylor (1970) reported beneficial effects of combining benomyl with nematicides that increase ozone sensitivity in preventing weather fleck of tobacco, Miller et al. (1976) combined either benomyl or carboxin with contact nematicides to attempt to reduce the severity of ozone damage to tobacco and bean plants. They found that bean plants grown in soil amended with benomyl or carboxin either alone or with nematicides were ozone resistant. They also found that the combination of benomyl with the nematicide, fensulfothion, induced ozone resistance in less time than did benomyl applied singly. Papple and Ormrod (1977) compared the efficacy of benomyl and carboxin in reducing ozone injury in turfgrasses. They found that benomyl effectively reduced ozone-induced injury but that carboxin did not perform well and had direct toxic effects on leaves of the three species studied. In 1978, Hofstra et al. found that benomyl and carboxin were equally effective in causing yield recovery in navy beans exposed to ozone although neither was as effective as EDU.

Other studies have looked at the possible benefits of benomyl with other chemicals thought to have similar effects. For example, Pellissier et al. (1972b) compared the effectiveness of benomyl and benomyl-folicote (an antitranspirant) treatments in reducing ozone injury in beans. They found that both benomyl and folicote used singly afforded the same degree of protection $(\sim 99 \%)$. They also found that a greater concentration of benomyl was needed when it was used as a soil drench rather than a foliar spray, although this was improved when a surfactant was added to benomyl in a soil drench.

Other derivatives of benzimidazole have been used to protect plants from ozone. Pellissier et al. (1971b) and Pellissier et al. (1972a) tested the possibility that thiabendazole applied to soil could impart protection to bean plants. They found that this chemical offered no protection from ozone and hypothesized that the failure of thiabendazole in protecting plants against ozone might have been due to low uptake. Seem (1972) found that the experimental fungicide NC 2983 conveyed a high degree of ozone resistance to bean plants with the complete elimination of leaf injury when applied at higher dosages. Curtis (1973) tested the efficiency of a number of oxathiin (carboxin) analogues apply as foliar sprays in protecting white bean from ozone injury. Curtis reported that carbathiin and the sulfoxide analogue were highly effective in reducing injury in plants grown both in controlled environments and in the field while other related oxathiin and thiazole analogues were ineffective. Curtis et al. (1973) showed that while treatment with protectants prior to ozone exposure was necessary to convey maximal protection, the effectiveness of antiozonant carboxin analogues was lost 5-10 days after application as foliar sprays in field-grown white bean plants. Curtis et al. $(1973,1974)$ and Rich et al. (1974) hypothesized that because carboxin is rapidly oxidized in soil and leaves that it was likely that the sulfoxide form was responsible for protection against ozone.

\subsubsection{Insecticides}

Koiwai et al. (1974) and Fukuda (1975a,b) published reports of studies testing numerous insecticides for the protection of tobacco in Japan. Koiwai et al. (1974) reported that while five 
out of ninety chemicals tested, namely 3,4-methylenedioxyphthaldehyde, benzimidazole, safroxane, xanthone and piperonal showed high protective capacities, they were all less effective than peperonyl butoxide. Fukuda et al. $(1975 \mathrm{a}, \mathrm{b})$ reported that while many of the benzimidazole, oxathiin and methylenedioxyphenyl derivatives were effective in controlling ozone injury to tobacco leaves, piperonyl butoxide was most effective, followed by benzimidazole and safroxane. Teso et al. (1979) studied the interactions of spectracide 25EC (diazinon) and lannate 90SP (methomyl) and there effects on bean plants. While they found that diazinon alleviated ozone injury, the combination of methomyl and ozone was more injurious than ozone alone. The use of antiozonant insecticides for the purpose of crop effects surveys would only be useful in situations where no crop loss due to insects occurs, otherwise it would be impossible to separate the benefits of insect control from those of ozone protection.

\subsubsection{Herbicides}

In the late 1970's and early 1980's Sung and Moore (1979) and Reilly and Moore (1982) published work on the effects of herbicides diphenamid, isopropalin and pebulate on ozone injury in tobacco. Sung and Moore (1979) found that sensitivity was either decreased or unaffected by herbicide application. Reilly and Moore (1982) found no consistent effect of pebulate but found that isopropalin and diphenamid reduced ozone injury for two to four weeks in field grown tobacco. Similarly, Carney et al. (1973) found that the intensity of ozone injury to tobacco was either increased, decreased or unaffected by the herbicides pebulate, benefin and chloramben, respectively.

While the many studies on the use of pesticides have demonstrated that a number of chemicals were promising for the protection of plants to ozone, most of these were abandoned shortly thereafter. Teso et al. (1979) nevertheless underscored the importance of research on air pollution-pesticide interactions as they may have a profound effect on integrated pest management. The possible dual purpose of some chemical agents in controlling pests and mitigating ozone effects remains interesting.

\subsection{The use of growth regulators, dusts and mechanical barriers and other chemicals as ozone protectants}

A summary of studies that have made use of growth regulators, dusts and mechanical barriers and various other chemicals is given in Table 3. Various growth regulators have been used in attempts at preventing ozone damage to plants. Seem (1972) used a whole host of growth regulators to protect bean plants from ozone injury. Seem found that while foliar application of $\mathrm{SADH}$ and Chloro IPC reduced ozone injury to leaves by approximately $50 \%$, chlormequat applied as a soil drench provided near complete protection. Fletcher et al. (1972) found that it was possible to considerably reduce ozone injury in bean plants by causing stomatal closure using ABA. Adedipe and Ormrod (1972) observed protective effects of N-6-benzyladenine (BA), gibberellic acid (GA) and indole acetic acid (IAA) from ozone in radish plants where BA was found to be the most effective protectant. Runeckles and Resh (1975) found that the cytokinins BA and kinetin both reduced the loss of chlorophyll caused by ozone and stimulated leaf growth but did not prevent ozone-induced decreases in stem and root growth. Cathey and 


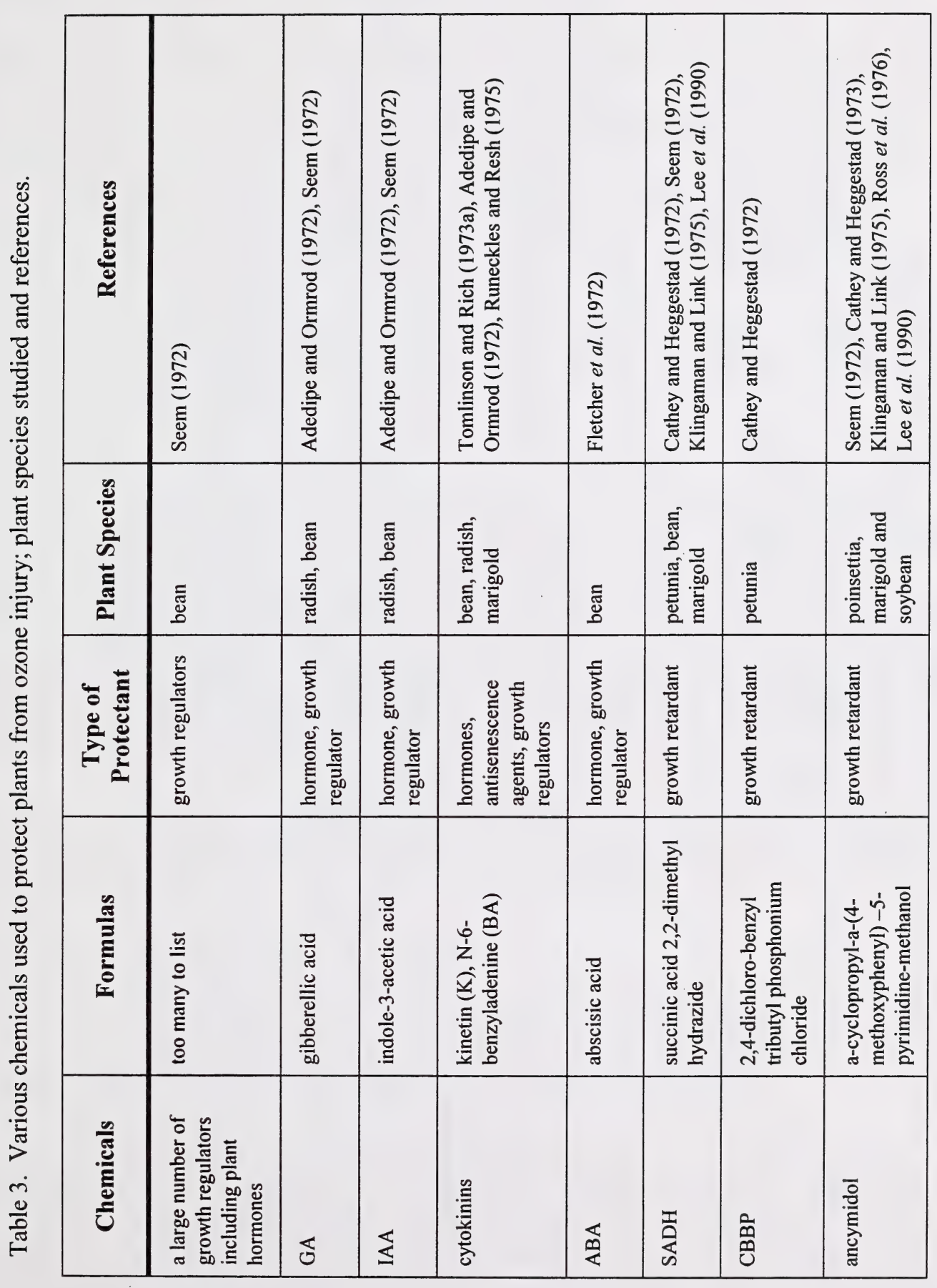

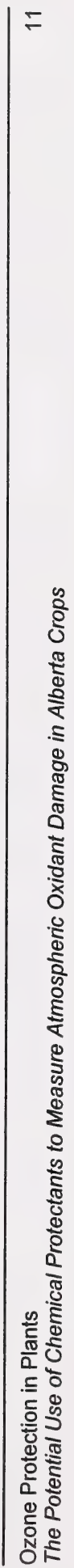




\begin{tabular}{|c|c|c|c|c|c|c|}
\hline 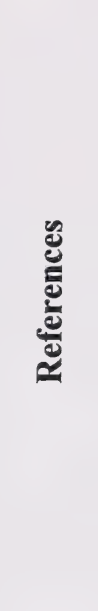 & 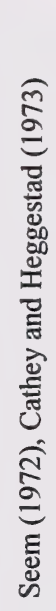 & 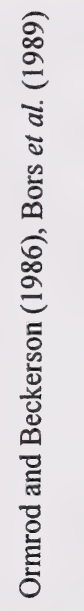 & 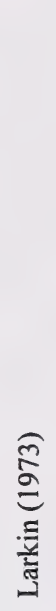 & 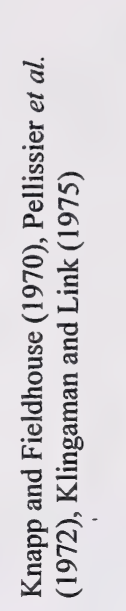 & 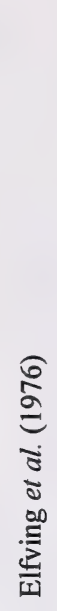 & 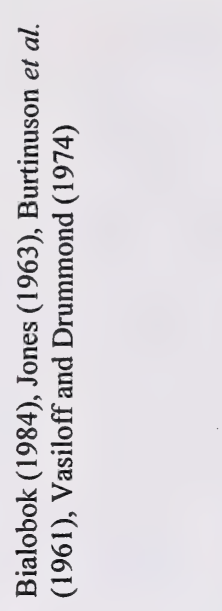 \\
\hline 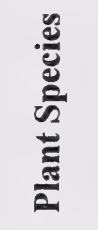 & 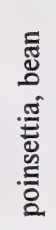 & 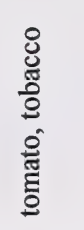 & 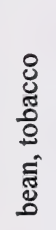 & 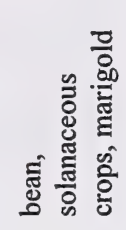 & $\frac{0}{\frac{0}{2}}$ & 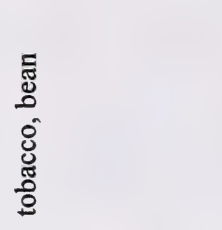 \\
\hline 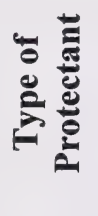 & 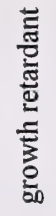 & 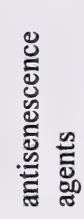 & 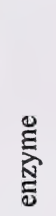 & 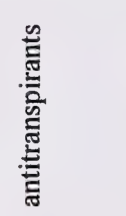 & 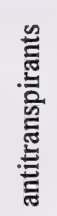 & $\begin{array}{l}\frac{0}{0} \\
\frac{y}{y}\end{array}$ \\
\hline 旁 & & 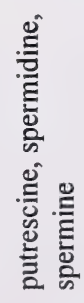 & & 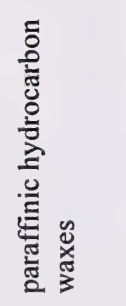 & & \\
\hline 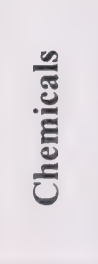 & 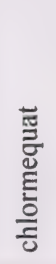 & 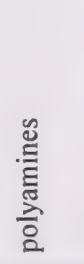 & 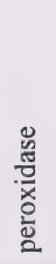 & $\begin{array}{l}00 \\
\frac{0}{0} \\
\frac{0}{0}\end{array}$ & 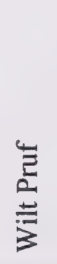 & 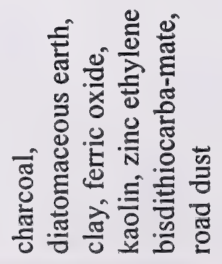 \\
\hline
\end{tabular}

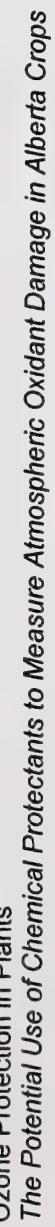


Heggestad (1972) found that a combination of SADH, L-ascorbic acid and the antitranspirant folicote was very effective in protecting petunia from ozone injury. In the same study they found that while soil drenches of the growth retardant CBBP reduced ozone effects by approximately $50 \%$, ancymidol and chlormequat offered less protection. In a later study, Cathey and Heggestad (1973) used the growth retardants, ancymidol and chlormequat, to protect poinsettias from ozone damage. Klingaman and Link (1975) found that while ancymidol offered protection against ozone injury to marigold leaves, it delayed anthesis and reduced flower count. Ross et al. (1976) also found significant protective effects of ancymidol against ozone in marigolds but did not report negative effects on flower production. More recently, Lee et al. (1990) found that ancymidol offered some protection against ozone in soybeans and reduced ozone-induced senescence. Other antisenescence compounds such as the polyamines putrescine, spermidine and spermine have been shown to offer some protection from ozone injury to tomato and tobacco (Ormrod and Beckerson 1986; Bors et al. 1989). Growth regulators affect a wide range of plant growth and development processes and therefore, are not specific to ozone protection and are not useful as protectants to establish effects of ozone on plants.

Dusts, waxes and antitranspirants have also been used to protect plants against ozone injury by reducing gas exchange. Substances such as charcoal, diatomaceous earth, clay, ferric oxide, kaolin and zinc ethylene bisdithiocarbamate have been used as physical barriers (Bertinuson et al. 1961; Jones 1963; Bialobok 1984). Knapp and Fieldhouse (1970) and Pellissier et al. (1972b) used the antitranspirant folicote to protect bean and solenaceous crops against ozone injury, while Elfving et al. (1976) used the antitranspirant Wilt Pruf to protect the foliage of apple trees. In 1974, Vasiloff and Drummond published a report of studies conducted to test the potential of road dust as an ozone protectant. They found that dusted pinto bean plants exposed to ozone for 6 hours suffered significantly fewer ozone lesions than did undusted plants. The effects of dusts waxes and antitranspirants are not specific and therefore, they are not useful as protectants to establish effects of ozone on plants.

While growth regulators, dusts, waxes and antitranspirants used singly or in combination offered some protection from ozone injury, the effects were generally inconsistent and confounding effects were observed.

\subsection{The use of antioxidants as ozone protectants}

A rather heterogeneous group of antioxidants have been found to prevent ozone damage with varied success primarily through the inhibition of oxidative processes (Table 4). While a number of chemicals described in other sections of this report have antioxidant properties, only those that appeared to be used primarily as antioxidants were placed into this section.

As an antioxidant, ascorbic acid and its salts have been used with success in reducing plant injury due to ozone in bean, celery, lettuce, barley, citrus and petunia (Freebairn 1960; Freebairn and Taylor 1960; Dass and Weaver 1968; Lee et al. 1990; Macher and Wasescha 1995). Soil application of potassium and calcium salts of ascorbic acid has been shown to protect bean plants from ozone injury (Freebairn 1963). In contrast, Siegel (1962) reported that ascorbic acid failed to provide appreciable protection from ozone to cucumber plants. Ozoban, an isomer of ascorbic 


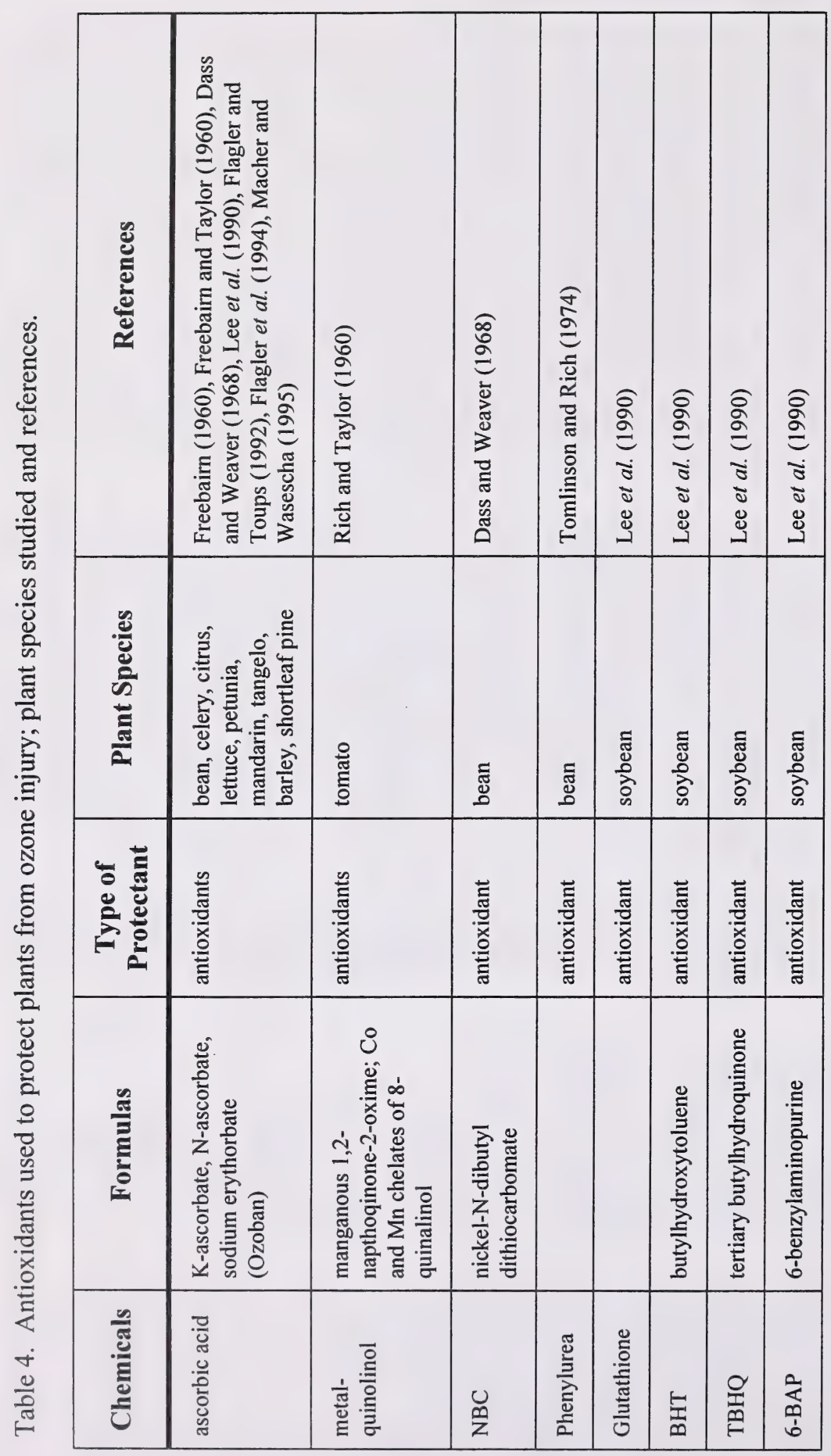

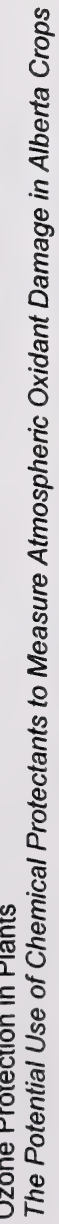


acid that is marketed by Pfizer Chemical Company as an antioxidant spray to reduce yield loss by ozone damage, was developed to protect Thompson seedless grapes from ozone damage in California. Field tests with Ozoban on grapes in Riverside, California, yielded mixed results with no consistent protective effects on yield of fruit (PM McCool in Flagler et al. 1994). Ozoban has also been used by Flagler and Toups (1992), Flagler and Lock (1994) and Flagler et al. (1994) to protect shortleaf pines from ozone injury in east Texas. In a short-term (1.5 years) study, Ozoban was found to provide some protection from ambient ozone. Recent studies by Kuehler and Flagler (1999) on loblolly pine showed that Ozoban can reduce photosynthetic rates in low-ozone environments and appeared to be harmful to chloroplast pigments in plants exposed to elevated ozone levels. Conflicting results as to the effectiveness of Ozoban in protecting pines from ozone injury are found in the literature and little information exists on its effects on annual crops. Extensive research would be required to establish the potential of Ozoban as a chemical protectant against ozone in crops of Alberta.

Field-grown tomato plants treated with manganous and cobaltous chelates of 8-quinolinol showed protection against visible ozone injury (Rich and Taylor 1960). Nickel-N-dibutyl dithiocarbamate was also found to be protective to bean plants and more protective than ascorbic acid (Dass and Weaver 1968). In 1974, Tomlinson and Rich reported that bean plants treated with the antioxidant phenylurea became highly resistant to ozone injury within 24 hours of application. The effects were shown to last for approximately 7 days. Based on experiments using leaf discs of bean, Tomlinson and Rich showed that phenylurea protected the chlorophyll pigment. Recently, Lee et al. (1990) tested the efficacy of a number of antioxidants in protecting soybean leaves from ozone injury. They found that while glutathione and BHT did not convey ozone protection, TBHQ and 6-BAP reduced ozone injury and chlorophyll damage to soybean leaves by more than $50 \%$. While Lee et al. (1990) showed that a number of antioxidants afforded protection from ozone, none were nearly as effective as EDU, which offered total protection against 2 to 4 hour exposures to $350 \mathrm{ppb}$ ozone.

\subsection{The use of ethylene diurea (EDU) as an ozone protectant}

Ethylene diurea (EDU - chemical name: N-[2-(2-oxo-1-imidazolidinyl)ethyl]-N'-phenylurea) is a systemic antioxidant that protects plant tissues from oxidant stipple and from early senescence caused by ozone. It was first developed by the duPont Chemical company in the 1970's specifically for this purpose. Although it contains urea, it apparently does not act as a plant nutrient, nor does it show pesticide or plant regulatory effects (Manning 1992). EDU does not affect photosynthesis, dark respiration and transpiration even when applied at dosages (1000 ppm soil drench) causing decreased growth of new tissues (Roberts 1987, Cannon et al. 1993). It appears to be specific for the suppression of ozone injury, having no effects on peroxyacetylnitrate (PAN) or $\mathrm{SO}_{2}$ injury (Cathey and Heggestad 1982a, Lee et al. 1992). While EDU is systemic, it apparently is not redistributed to new tissues and repeated applications are required to protect newly-emerging leaves. The precise nature of the protective effects of EDU remains unclear.

The uptake and partitioning of EDU has recently been studied using HPLC (Regner-Joosten $e t$ al. 1994). Autoradiographic studies conducted by Roberts et al. (1987) on woody plants showed 
that EDU injected into stems accumulated in the leaves and persisted for approximately 10 days, a time line congruent with many reports on the length of protection afforded by an EDU application. EDU has been used to modify $\mathrm{O}_{3}$ sensitivity in many plant species (Manning 1988; Manning and Krupa 1992). In studies conducted in the ozone-polluted regions of eastern Canada in the late 1970's and early 1980's, researchers reported that EDU reduced and/or delayed the appearance of ozone damage to developing foliage and delayed plant senescence and leaf abscission. These findings showed promise for the use of EDU as a general protectant against ozone damage.

Since these early reports, a multitude of studies have been conducted using EDU as an ozone protectant. Researchers have sought to establish optimized protocols for the use of EDU in programs aiming at the quantification of the effects of ozone on vegetation and to understand the process by which EDU conveys resistance to ozone. From the extensive literature on the subject, it is apparent that the effects of EDU are species- and sometimes cultivar-specific, that the dose, frequency and mode of application are critical and that one must take into consideration the length and frequency of ozone exposure as well as environmental conditions in standardizing the EDU method. Table 5 provides a summary of experiments conducted since the development of EDU in the late 1970s.

\section{Methods of Application}

In 1974, Tomlinson and Rich reported on the use of phenylurea to protect bean leaves from ozone injury and to inhibit senescence. In 1978, Carnahan et al. described the beneficial effects of a new chemical that contained phenylurea, EDU, in increasing resistance to ozone in pinto beans by 30 -fold. They performed full dose response experiments using both soil drenches and foliar applications. They suggested that EDU would become a useful survey tool in the identification and quantification of ozone damage in vegetation. EDU was soon put to the test and in the same year Musselman et al. (1978) and Cathey and Heggestad (1978) described beneficial effects of EDU in grapevines and on a number of florist and nursery crops, respectively. While Musselman et al. found that soil drenches were largely ineffective, Cathey and Heggestad found drenches to be as effective as foliar applications. Also in 1978, Clarke et al. published results of tests performed to verify the potential benefits of EDU application to potato plants exposed to ozone. They found that soil application of EDU was highly effective in preventing foliar injury but tuber yield, size and specific gravity were similar whether plants had been treated or not.

Applications of EDU as a soil drench and as a foliar spray have been successful in conveying resistance to ozone injury in plants but the possibility of soil accumulation of EDU and the subsequent possibility of toxicity argue for the use of foliar applications. Perhaps the greatest factors determining the appropriate mode of application are practical issues. On the large scale and in the field, it is perhaps not feasible to apply soil drenches at all stages of plant development, especially in crops that are not grown in rows such as hay and broadcasted cereal crops. The application of EDU as a soil drench at field scale would require large volumes of solution while surface applications would depend on precipitation to carry the chemical to the 


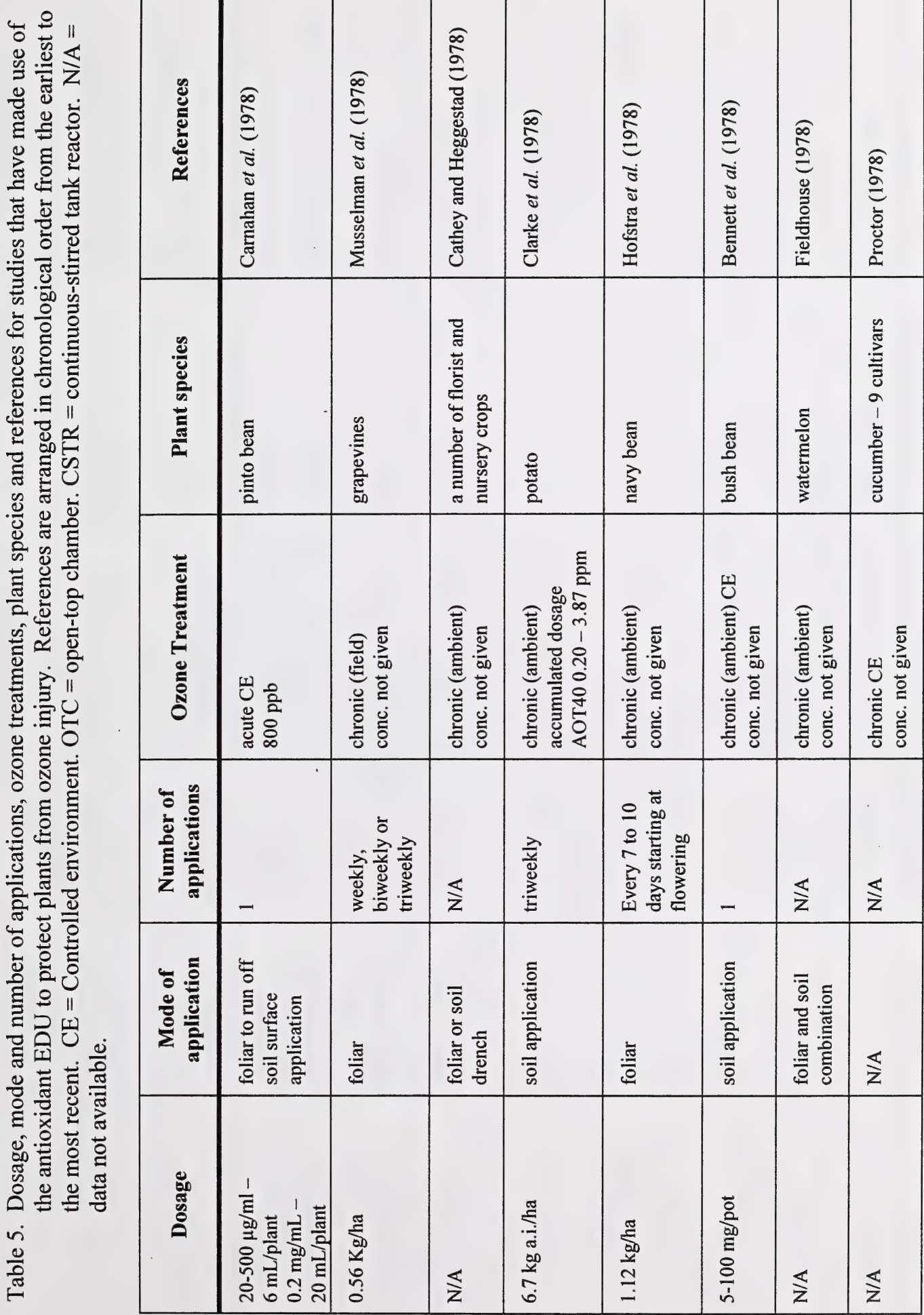

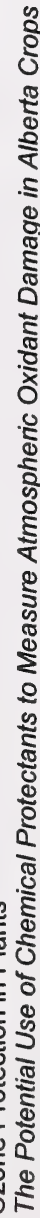




\begin{tabular}{|c|c|c|c|c|c|c|c|c|c|c|}
\hline 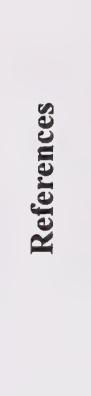 & 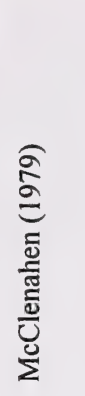 & 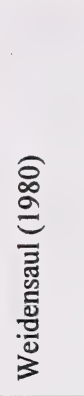 & 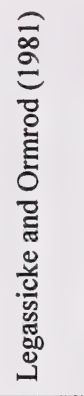 & & 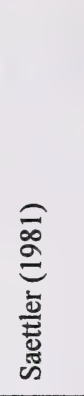 & 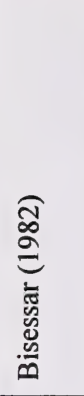 & 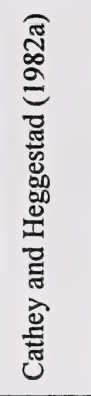 & 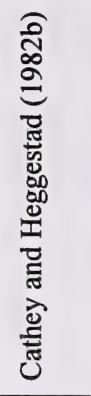 & 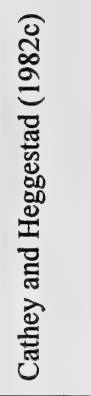 & 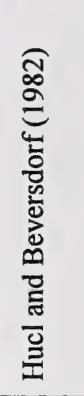 \\
\hline 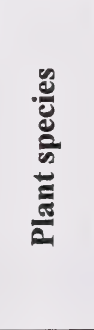 & 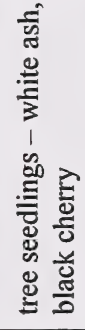 & 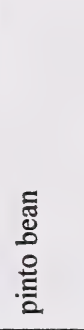 & 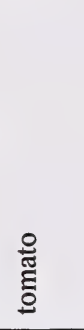 & & 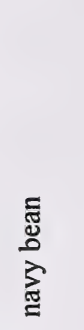 & $\begin{array}{l}\frac{0}{\pi} \\
\frac{\pi}{2} \\
\text { L }\end{array}$ & 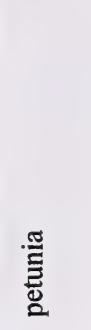 & 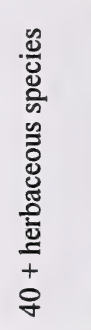 & 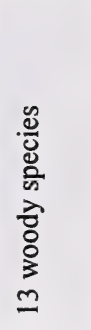 & 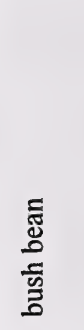 \\
\hline 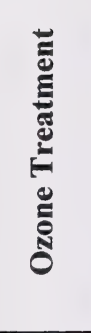 & 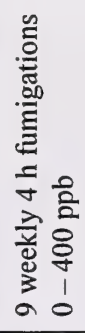 & 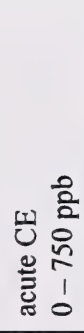 & 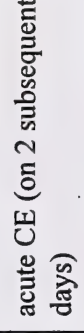 & 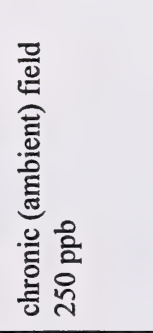 & 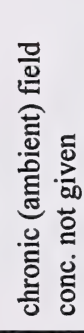 & 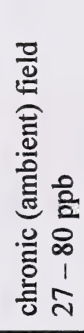 & 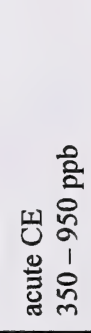 & 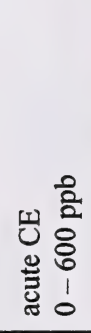 & 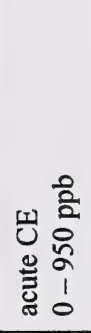 & 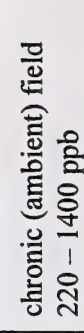 \\
\hline 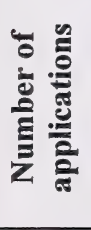 & 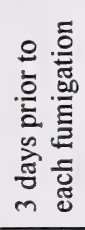 & 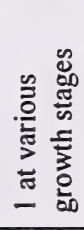 & - & 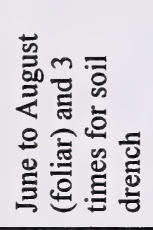 & $N 0$ & 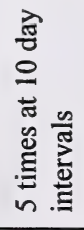 & - & - & - & 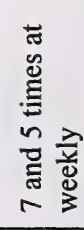 \\
\hline 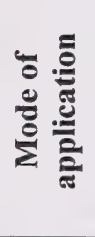 & $\frac{. \overline{\frac{\pi}{0}}}{\frac{0}{0}}$ & 咅 & 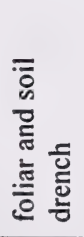 & 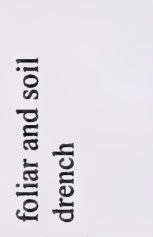 & 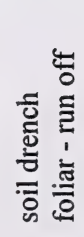 & 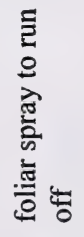 & 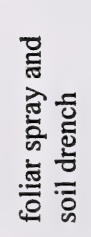 & 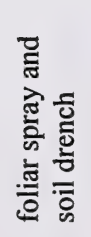 & 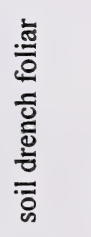 & 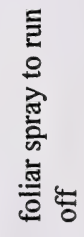 \\
\hline 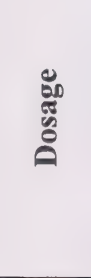 & $\begin{array}{l}\text { E } \\
\text { 응 } \\
\text { ○े }\end{array}$ & $\begin{array}{l}\frac{a}{20} \\
\text { ab } \\
0 \\
o \\
0 \\
0 \\
0\end{array}$ & 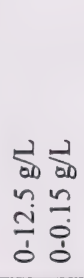 & 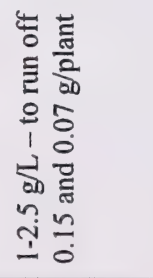 & 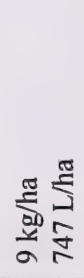 & 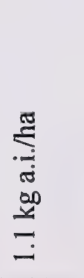 & 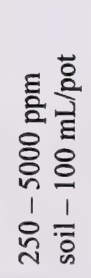 & 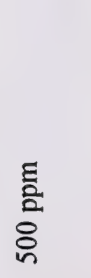 & 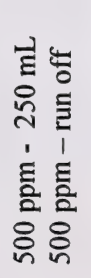 & 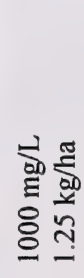 \\
\hline
\end{tabular}

๕ั้

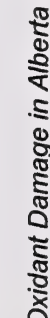
ปั 


\begin{tabular}{|c|c|c|c|c|c|c|c|c|c|}
\hline$\frac{\mathscr{d}}{0}$ & 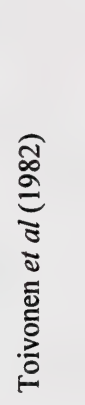 & 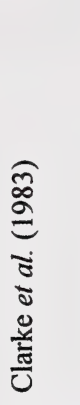 & 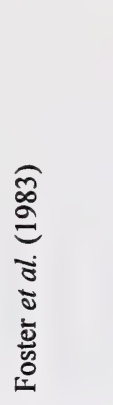 & 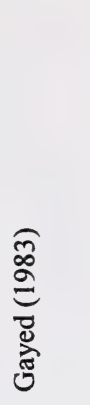 & 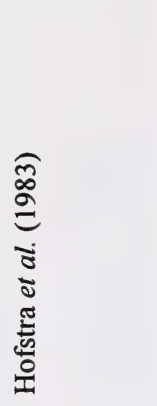 & 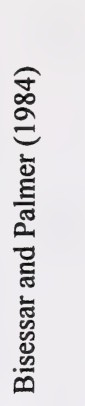 & 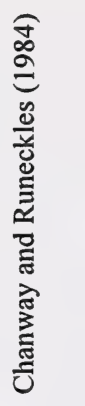 & 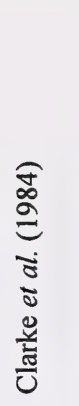 & 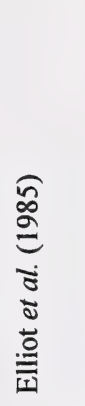 \\
\hline 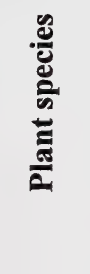 & 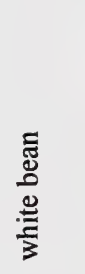 & 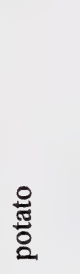 & $\begin{array}{l}\frac{0}{\pi} \\
\text { 을 }\end{array}$ & $\begin{array}{l}\stackrel{0}{0} \\
\text { ஜूँ } \\
\stackrel{0}{0}\end{array}$ & 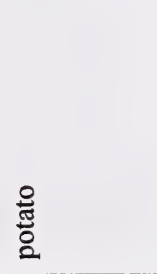 & $\begin{array}{l}\stackrel{0}{0} \\
\tilde{\Xi} \\
\text { \& }\end{array}$ & 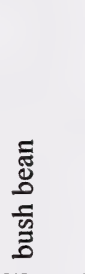 & 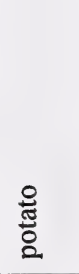 & 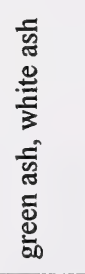 \\
\hline 氖 & 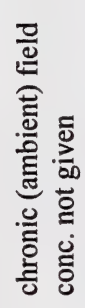 & 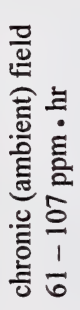 & 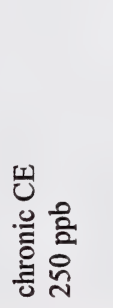 & 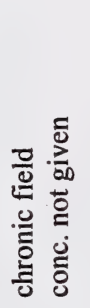 & 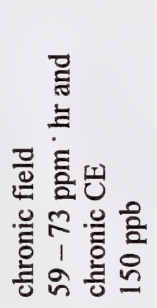 & 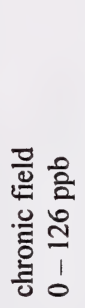 & 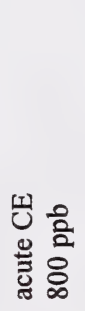 & 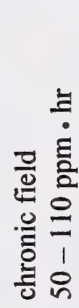 & 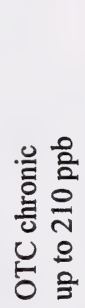 \\
\hline 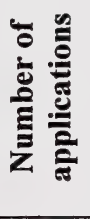 & 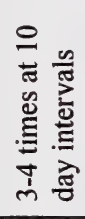 & 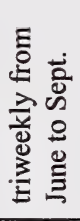 & 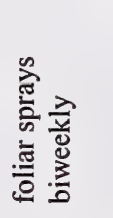 & 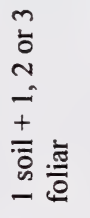 & 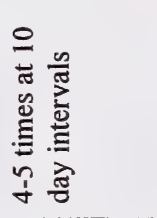 & 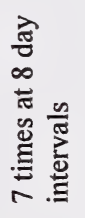 & - & $\frac{\nwarrow}{z}$ & $\begin{array}{l}\frac{\lambda}{d} \\
\frac{\vec{d}}{3}\end{array}$ \\
\hline 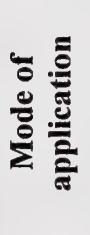 & 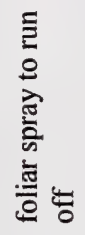 & $\begin{array}{l}\frac{\overline{0}}{0} \\
\text { 힘 } \\
\overline{\overline{0}}\end{array}$ & 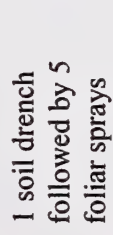 & 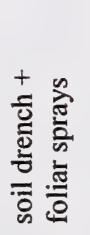 & 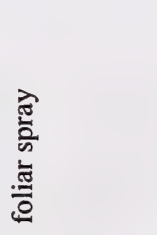 & 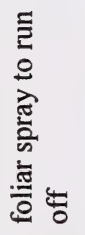 & $\overline{\bar{\sigma}}$ & $\frac{\nwarrow}{z}$ & $\begin{array}{l}\frac{\overline{0}}{0} \\
\text { 흠 } \\
\overline{0}\end{array}$ \\
\hline $\begin{array}{l}\text { : } \\
\text { है } \\
\text { है } \\
0\end{array}$ & 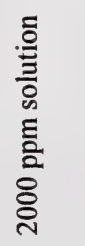 & 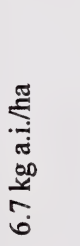 & 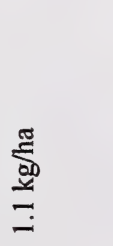 & 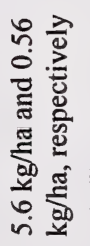 & 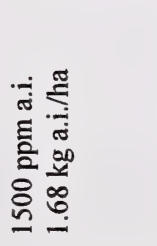 & 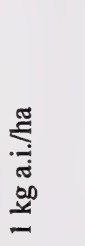 & 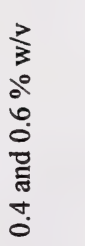 & $\frac{\nwarrow}{z}$ & 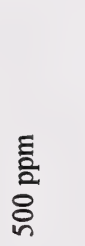 \\
\hline
\end{tabular}

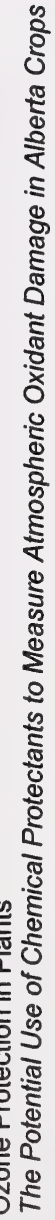




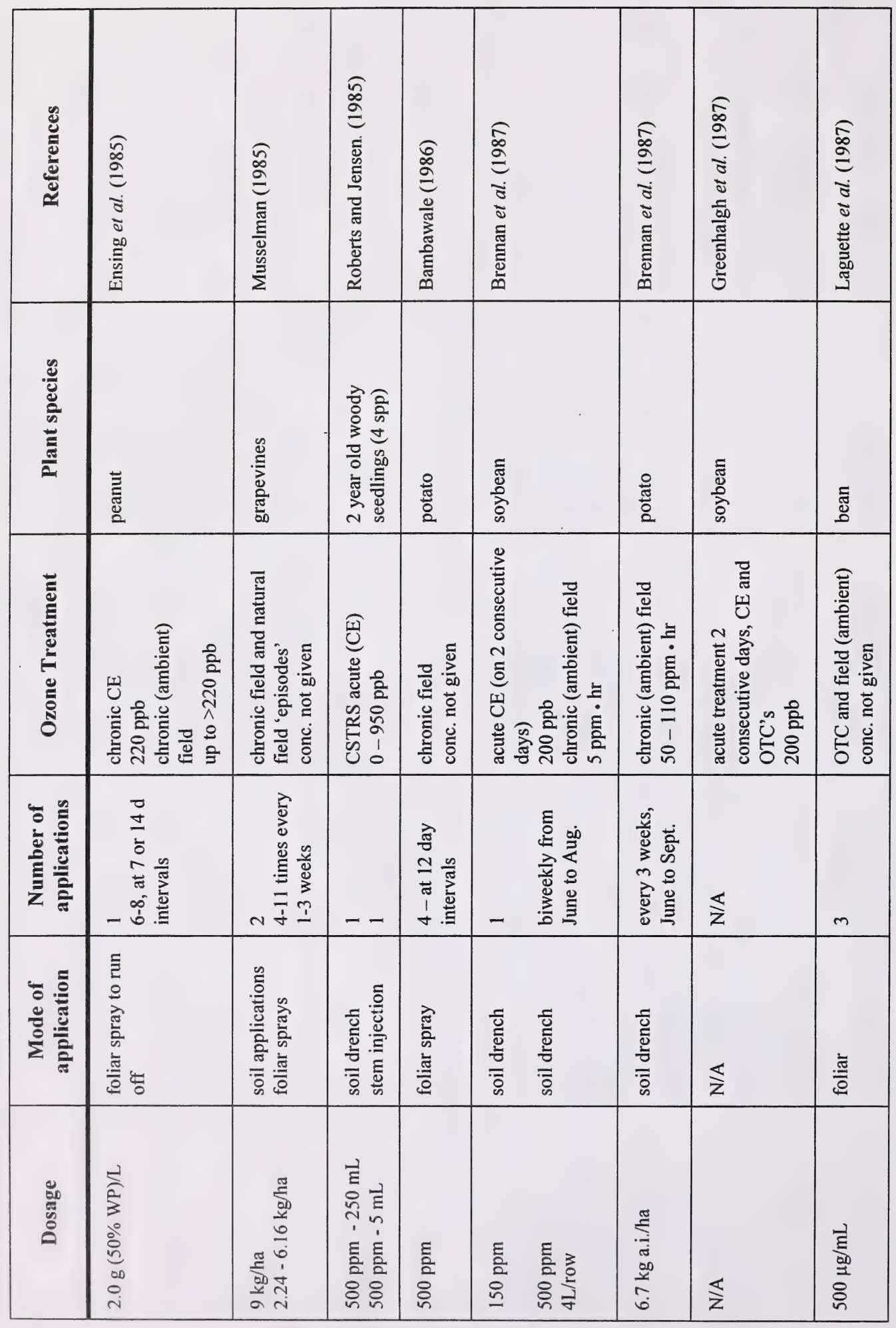




\begin{tabular}{|c|c|c|c|c|c|c|c|c|}
\hline 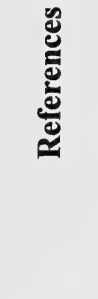 & 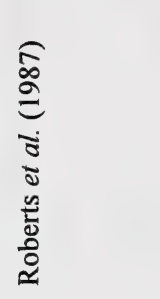 & 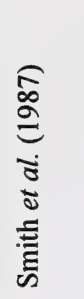 & 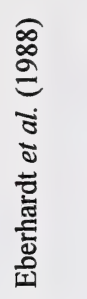 & 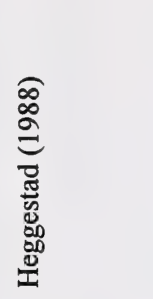 & 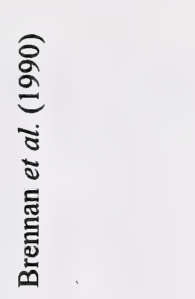 & 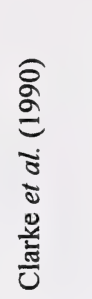 & 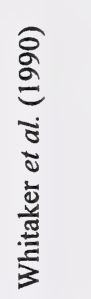 & 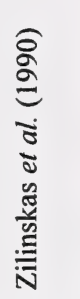 \\
\hline 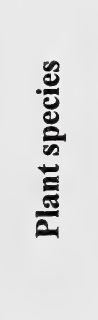 & 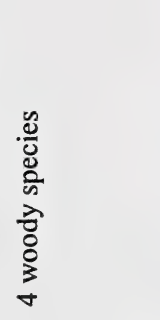 & 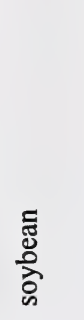 & 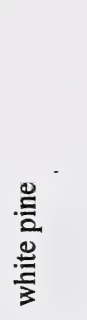 & 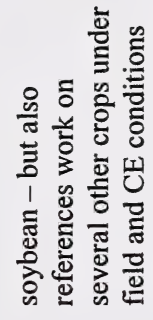 & 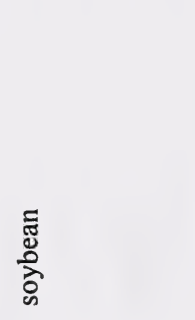 & 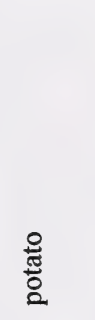 & 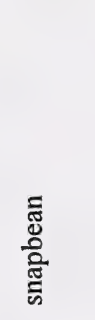 & \\
\hline 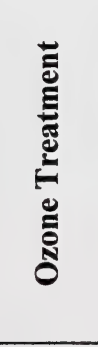 & 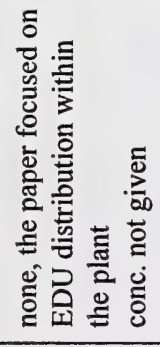 & 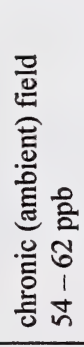 & 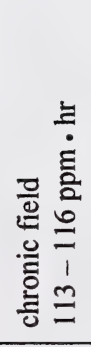 & 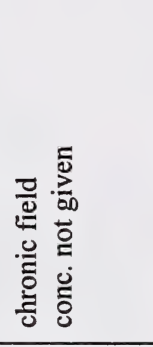 & 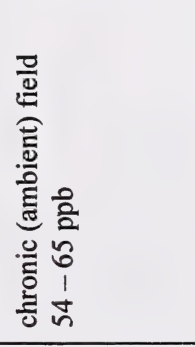 & 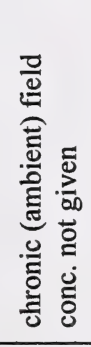 & 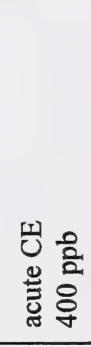 & 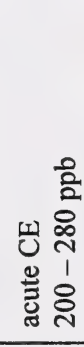 \\
\hline 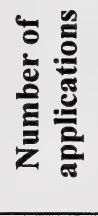 & - & $\begin{array}{l}\text { 章 } \\
\text { 晜 }\end{array}$ & 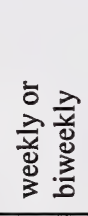 & $\begin{array}{l}\text { 咅 } \\
\text { 晜 }\end{array}$ & $\begin{array}{l}\frac{\lambda}{3} \\
\frac{\pi}{3} \\
\frac{3}{3}\end{array}$ & 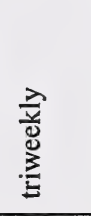 & - & - \\
\hline 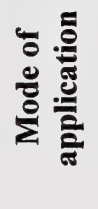 & 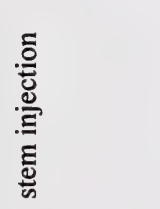 & 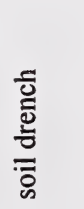 & 売 & $\begin{array}{l}\overline{0} \\
\overline{0} \\
\overline{0} \\
\overline{0} \\
\overline{0}\end{array}$ & $\begin{array}{l}\overline{0} \\
\overline{0} \\
\overline{0} \\
\overline{\overline{0}} \\
\dot{0}\end{array}$ & 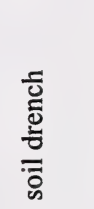 & 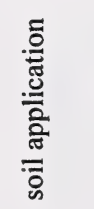 & $\begin{array}{l}\overline{\overline{0}} \\
\overline{\bar{\omega}} \\
\overline{\overline{0}} \\
\overline{\bar{b}}\end{array}$ \\
\hline 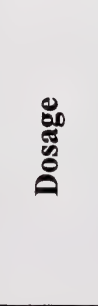 & 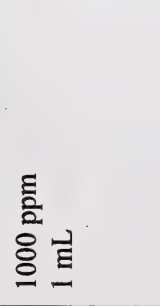 & 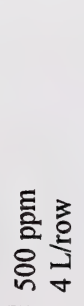 & $\begin{array}{l}\text { 흠 } \\
\text { ò }\end{array}$ & 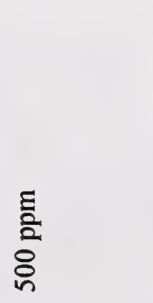 & 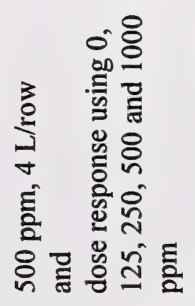 & 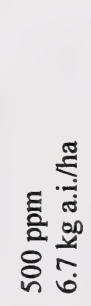 & 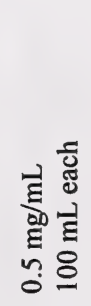 & 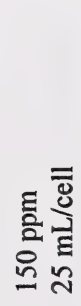 \\
\hline
\end{tabular}

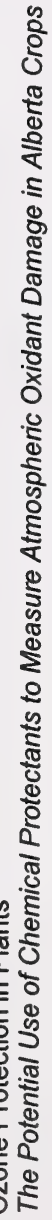




\begin{tabular}{|c|c|c|c|c|c|c|c|c|c|}
\hline 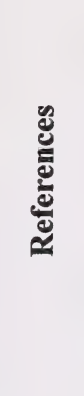 & 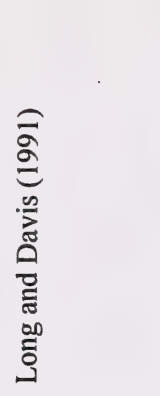 & 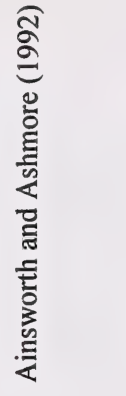 & 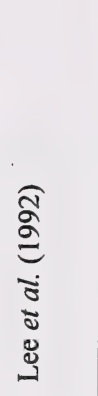 & 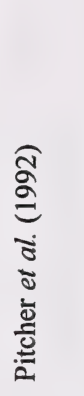 & 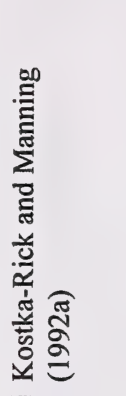 & 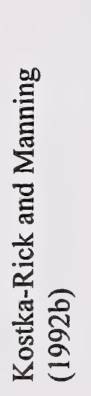 & 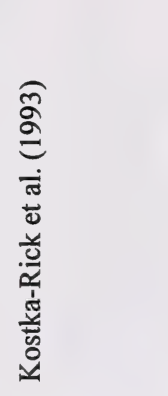 & 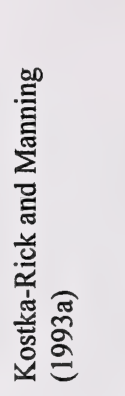 & \\
\hline 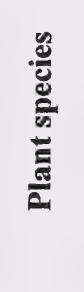 & 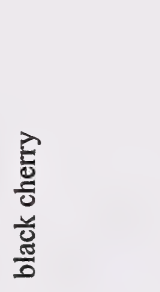 & 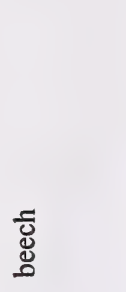 & 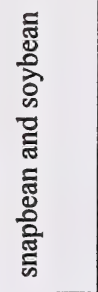 & 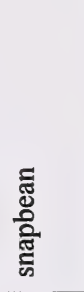 & 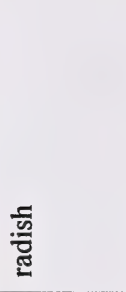 & 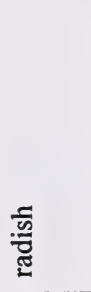 & 点 & 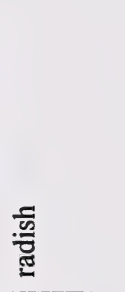 & \\
\hline 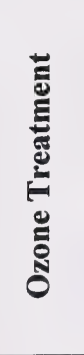 & 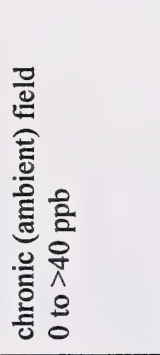 & 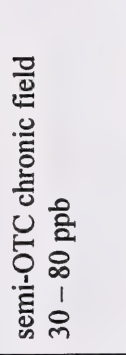 & 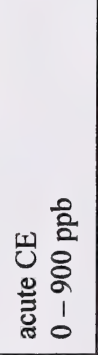 & 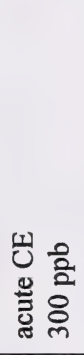 & 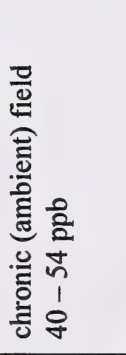 & 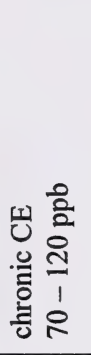 & 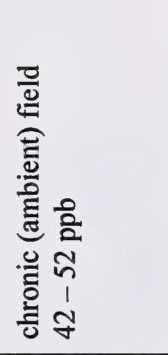 & 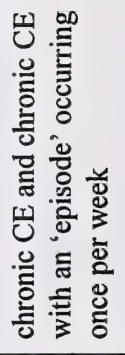 & $\begin{array}{l}0 \\
\frac{2}{2} \\
\frac{0}{2} \\
\frac{0}{2}\end{array}$ \\
\hline 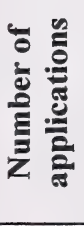 & 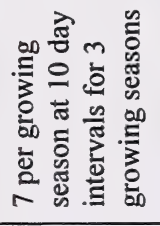 & 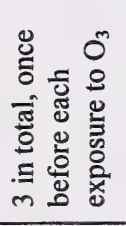 & - & - & - & - & - & $\sim$ & \\
\hline 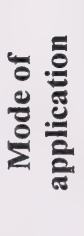 & 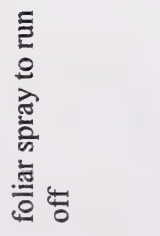 & 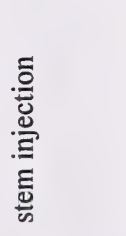 & $\begin{array}{l}\frac{}{0} \\
\overline{0} \\
\frac{\operatorname{tg}}{\overline{0}} \\
\overline{0}\end{array}$ & 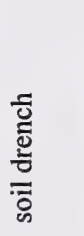 & 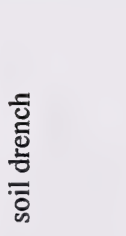 & 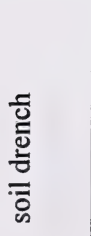 & 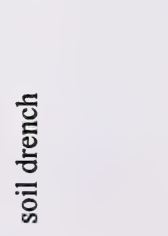 & 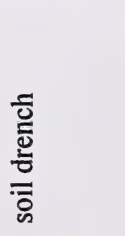 & \\
\hline $\begin{array}{l}: 0 \\
\stackrel{0}{E} \\
\stackrel{5}{0} \\
\stackrel{0}{0}\end{array}$ & 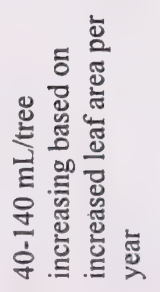 & 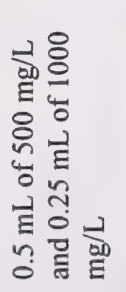 & 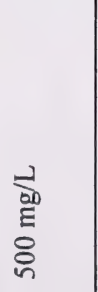 & 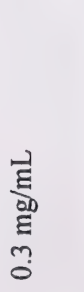 & 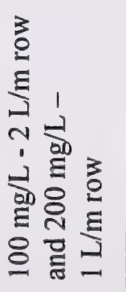 & 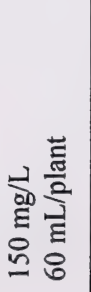 & 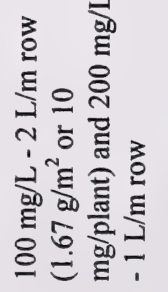 & 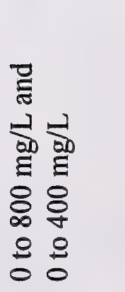 & 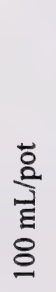 \\
\hline
\end{tabular}




\begin{tabular}{|c|c|c|c|c|c|c|c|c|c|}
\hline 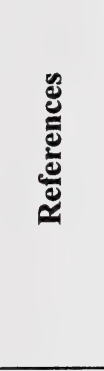 & 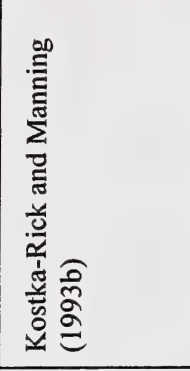 & & 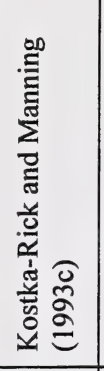 & 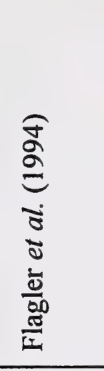 & & 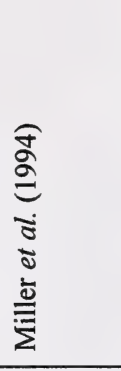 & 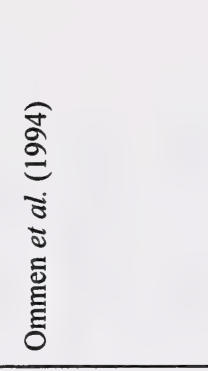 & 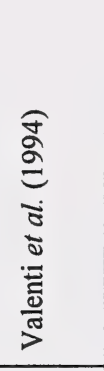 & 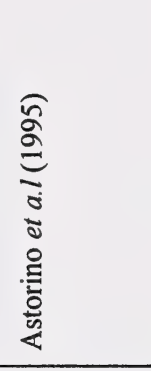 \\
\hline 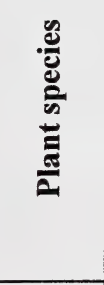 & 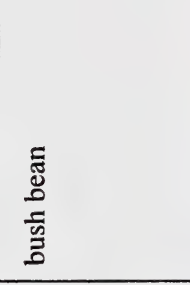 & & 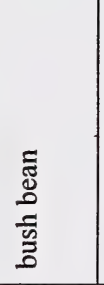 & 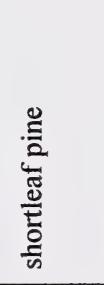 & & 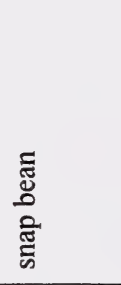 & 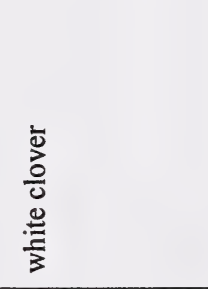 & $\begin{array}{l}\stackrel{8}{0} \\
\text { ỡ }\end{array}$ & 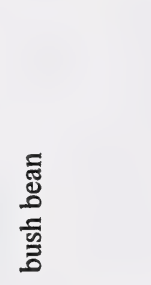 \\
\hline 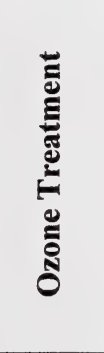 & 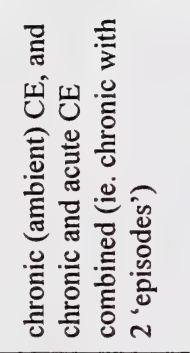 & \begin{tabular}{l|}
0 \\
$\frac{0}{2}$ \\
$\frac{2}{2}$ \\
$\frac{1}{8}$ \\
8
\end{tabular} & 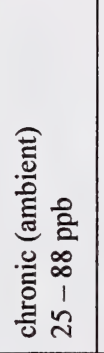 & 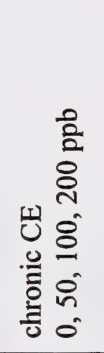 & 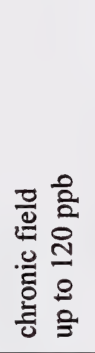 & 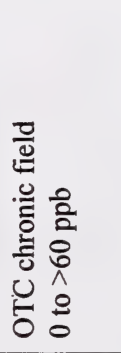 & 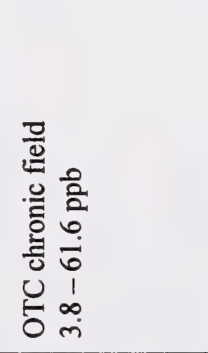 & 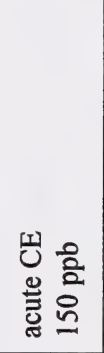 & 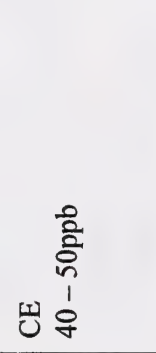 \\
\hline 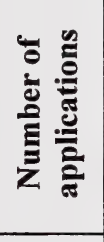 & 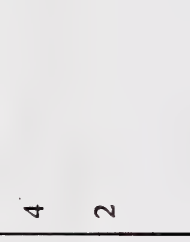 & & $\mathrm{N}$ & $\begin{array}{l}\text { 츨 } \\
\text { 产 } \\
\text { E }\end{array}$ & $\begin{array}{l}\text { 를 } \\
\text { 言 }\end{array}$ & $\nabla$ & 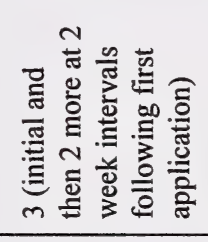 & - & 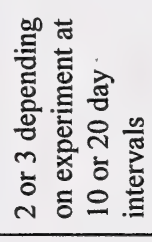 \\
\hline 施 & 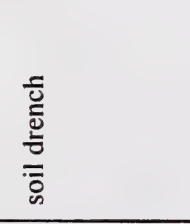 & & 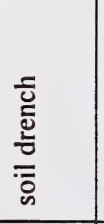 & 惡 & 馵 & 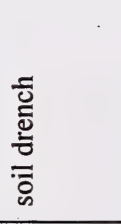 & 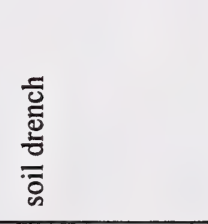 & 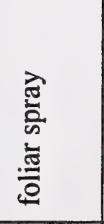 & 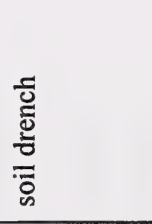 \\
\hline 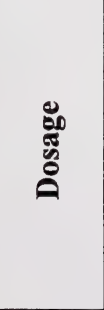 & 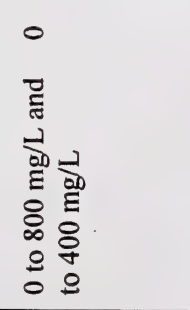 & 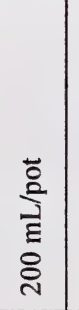 & 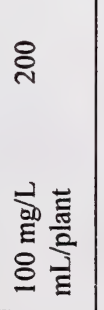 & 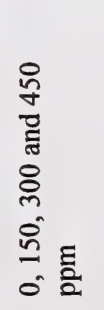 & 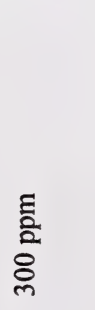 & 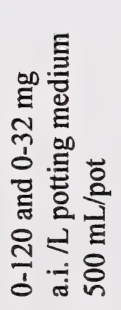 & 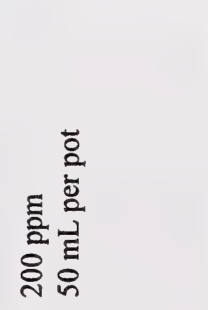 & 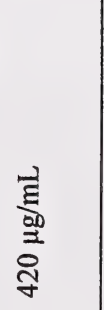 & 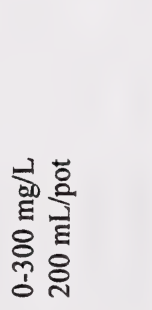 \\
\hline
\end{tabular}




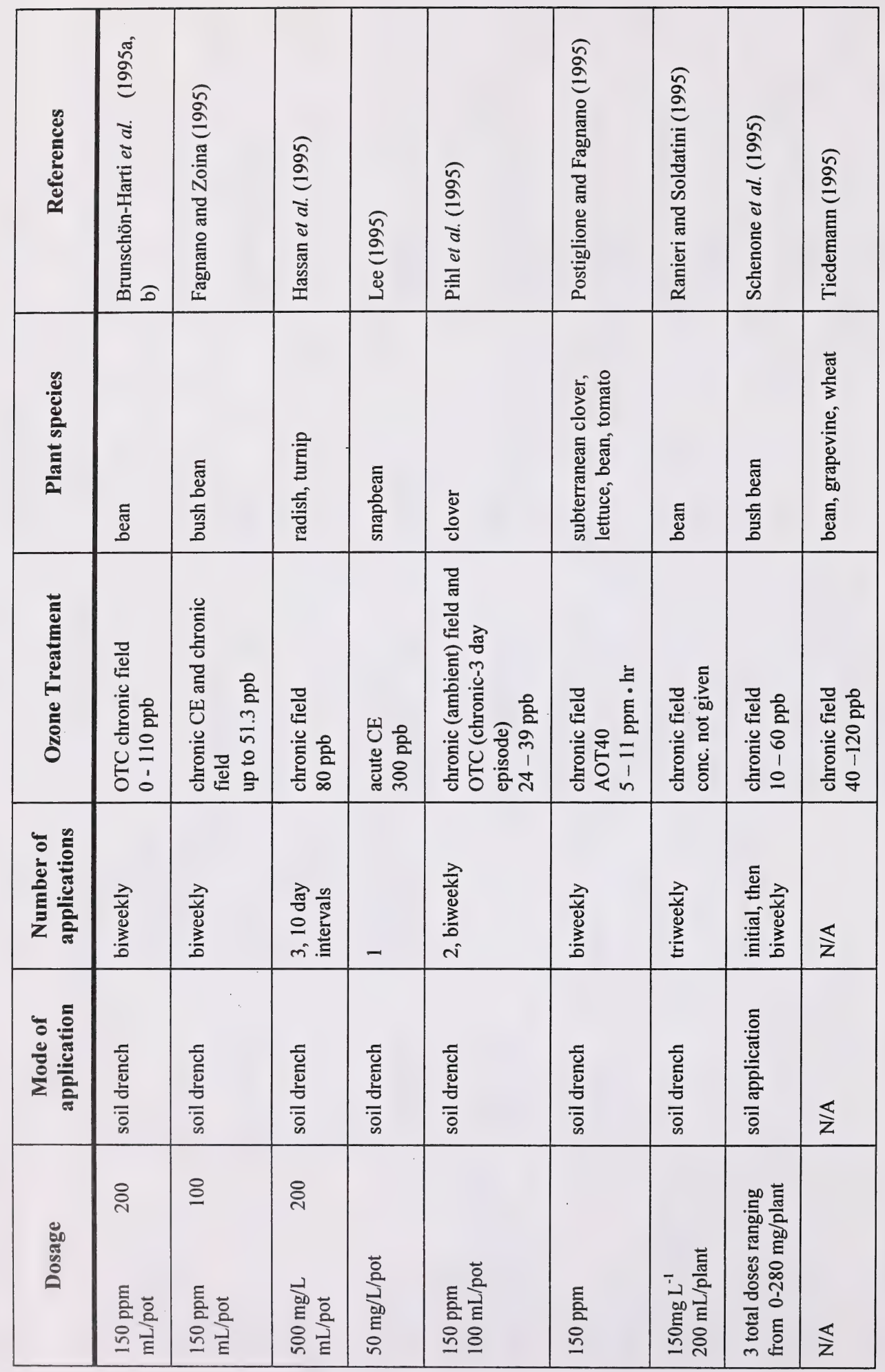




\begin{tabular}{|c|c|c|c|c|c|c|c|c|c|}
\hline d & 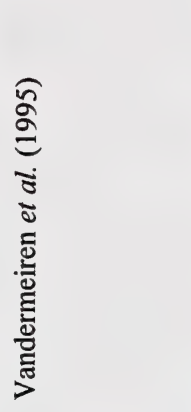 & 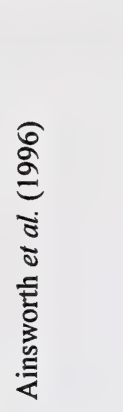 & 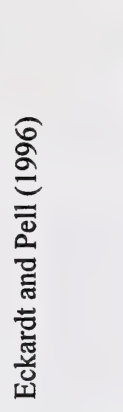 & 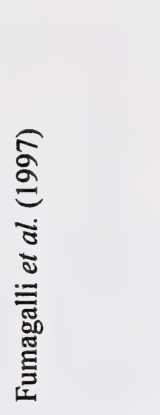 & 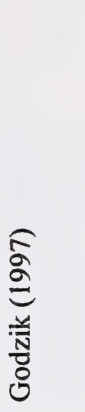 & 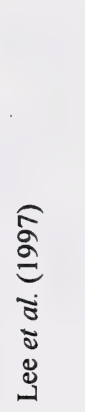 & 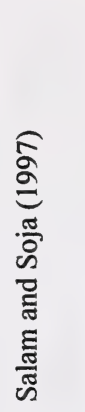 & 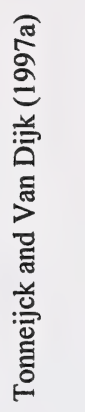 & 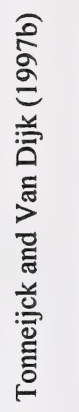 \\
\hline 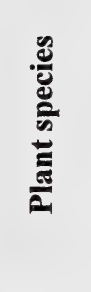 & 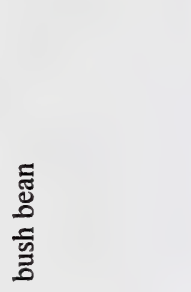 & $\begin{array}{l}\frac{\hbar}{0} \\
\frac{0}{2} \\
\frac{0}{2} \\
\frac{0}{2}\end{array}$ & 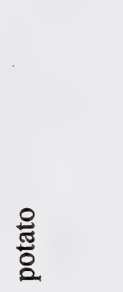 & $\begin{array}{l}\frac{\overline{0}}{0} \\
\frac{0}{0} \\
\frac{0}{3} \\
\frac{0}{3}\end{array}$ & 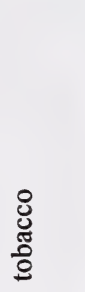 & 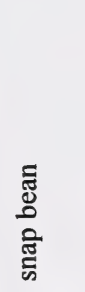 & $\begin{array}{l}\frac{\grave{0}}{0} \\
\frac{0}{0} \\
\text { d }\end{array}$ & 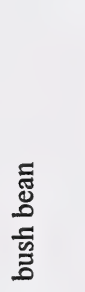 & 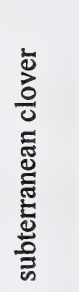 \\
\hline 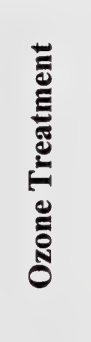 & 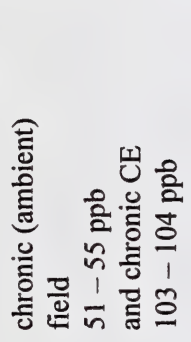 & 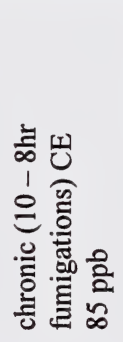 & 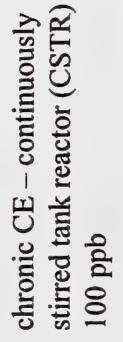 & 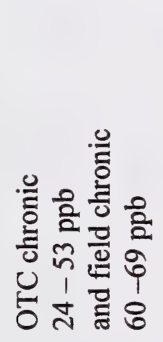 & 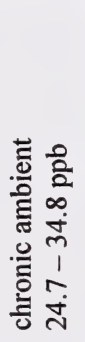 & 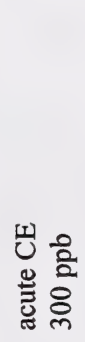 & 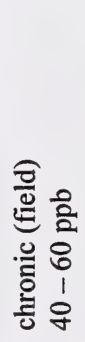 & 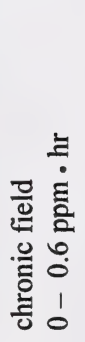 & 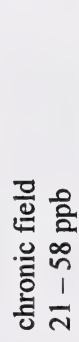 \\
\hline 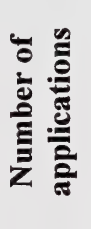 & 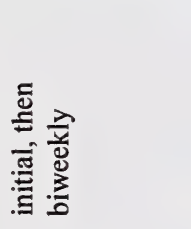 & - & - & 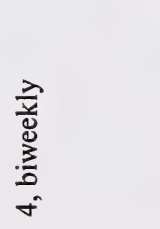 & - & - & $\begin{array}{l}\frac{\lambda}{y} \\
\frac{0}{0} \\
.0\end{array}$ & 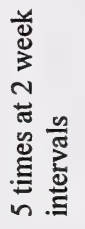 & 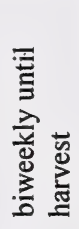 \\
\hline 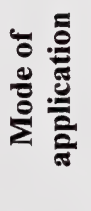 & $\begin{array}{l}\frac{5}{0} \\
\frac{0}{2} \\
\frac{0}{\overline{0}}\end{array}$ & 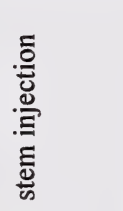 & 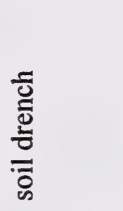 & $\begin{array}{l}\frac{\overline{0}}{\tilde{D}} \\
\frac{0}{0} \\
\frac{0}{0}\end{array}$ & 胥 & 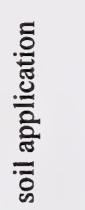 & 点 & 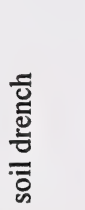 & 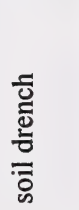 \\
\hline 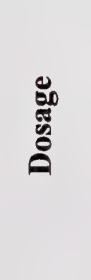 & 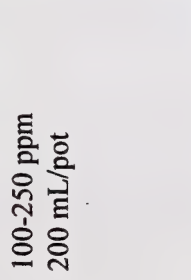 & 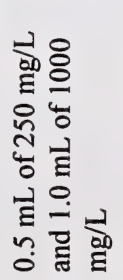 & 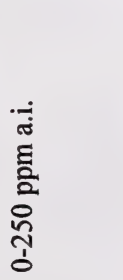 & 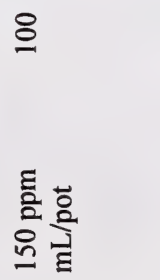 & 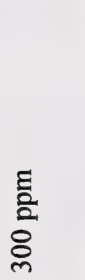 & 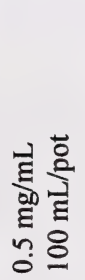 & $\frac{\nwarrow}{z}$ & 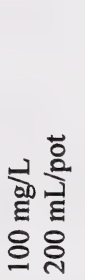 & 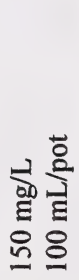 \\
\hline
\end{tabular}

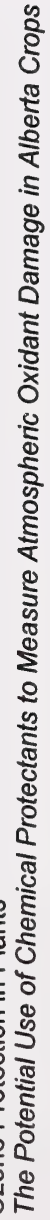




\begin{tabular}{|c|c|c|c|c|c|c|c|}
\hline 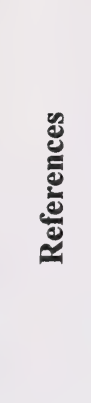 & 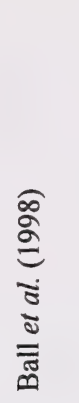 & 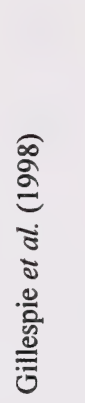 & 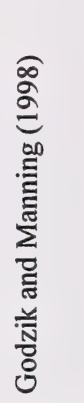 & 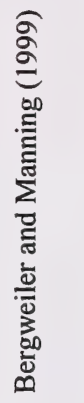 & 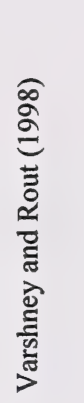 & 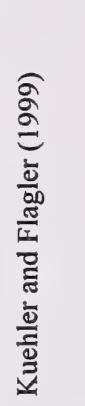 & 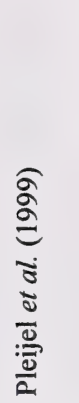 \\
\hline 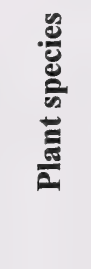 & 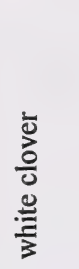 & 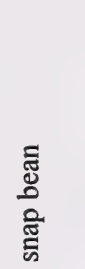 & $\begin{array}{l}\text { ठ্ } \\
\text { : } \\
\text { : }\end{array}$ & 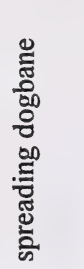 & 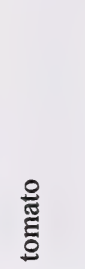 & 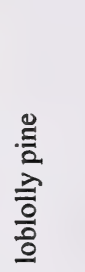 & 点 \\
\hline 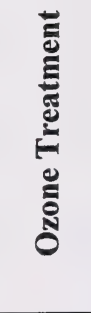 & 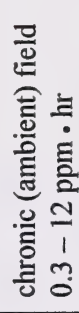 & 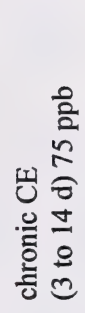 & 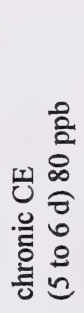 & 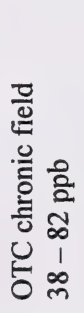 & 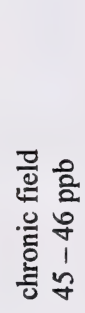 & 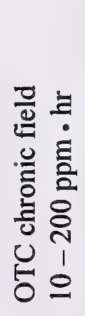 & 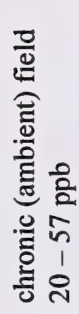 \\
\hline 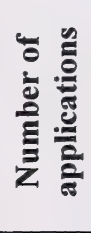 & 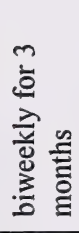 & - & - & 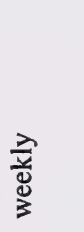 & 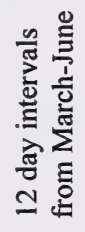 & $\begin{array}{l}\frac{\lambda}{y} \\
\frac{3}{0}\end{array}$ & 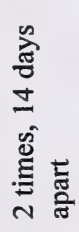 \\
\hline 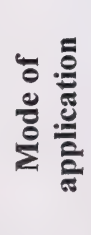 & $\begin{array}{l}\frac{\overline{0}}{0} \\
\frac{0}{0} \\
\frac{\overline{0}}{0}\end{array}$ & 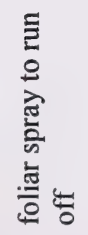 & 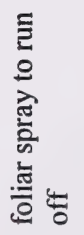 & 离 & 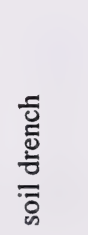 & 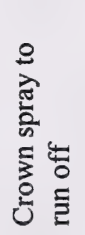 & 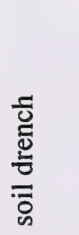 \\
\hline 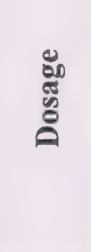 & 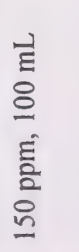 & $\begin{array}{l}E \\
\frac{2}{2} \\
8 \\
\frac{8}{1} \\
\frac{1}{2} \\
\end{array}$ & 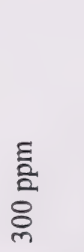 & 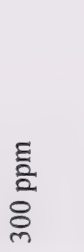 & 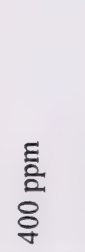 & 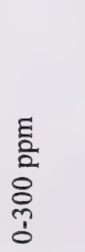 & 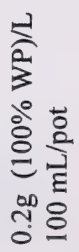 \\
\hline
\end{tabular}

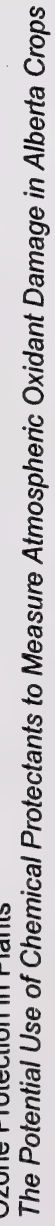


plant roots. Foliar application appears to be the most practical especially for large-scale field studies.

\section{Application Dose}

As emphasized by Manning (1988, 1992, 1995) and Kostka-Rick and Manning (1993a,b), it is of paramount importance that proper dose response studies be conducted prior to the use of EDU as a survey tool for the measurement of ozone effects. Dose response experiments will not only allow for the determination of the optimal dosage of EDU to convey resistance to ozone but will also allow for the determination of possible side-effects of EDU by application of EDU to plants in the absence of ozone in parallel to application to plants being exposed to ozone. In the first studies by Carnahan et al. (1978) in which plants were exposed to acute ozone treatments, various dosages of EDU were tested. Since then, while proper dose response protocols have been followed in many experiments, several studies have been conducted using EDU dosages that were extrapolated from previous experiments. Some of these extrapolations were done from acute to chronic ozone studies and have led to under- or over-dosages of EDU. In these cases, EDU has led to ineffective protection and to EDU-induced toxicity resulting in reduced yields. Manning (1992) provides a review of uses and misuses of EDU.

Ever since Carnahan et al. (1978) found that a 500 ppm EDU spray applied to foliage was the optimal rate for protecting bean plants from acute exposure to ozone, many studies have shown this rate of application to be suitable. For example, Cathey and Heggestad (1982a,b) conducted exposure/response screening trials on 4 cultivars of petunia and 44 species of herbaceous plants and found that $500 \mathrm{ppm}$ as a foliar spray or soil drench was optimal. Soil drenches at $500 \mathrm{ppm}$ EDU were also shown to be best for woody species (Cathey and Heggestad 1982c). Based on a number of studies, $500 \mathrm{ppm}$ EDU is the appropriate concentration to protect plants from acute ozone injury (Carnahan et al. 1978; Cathey and Heggestad 1982a,b,c; Weidensaul 1980). Based on these findings, later studies making use of EDU to protect plants against chronic exposures to ozone were designed with the assumption that repeated, weekly or biweekly, applications of EDU would not be injurious and that the same concentration (500 ppm) of EDU would be protective. This method was used with varied success (Bambawale 1986; Brennan et al. 1990; Clarke et al. 1983, 1990; Heggestad 1988; Hofstra et al. 1983; Legassicke and Ormrod 1981; Toivonen et al. 1982). In several of these studies plants were over-dosed with EDU and negative effects such as browning of leaf edges and reductions in yield were found. In recent studies EDU has been used without proper preliminary dose-response studies. For example, the standard protocol for the UN-ECE ICP-Crops program is to test various species and cultivars for ozone damage in pot studies in which EDU at a concentration of $150 \mathrm{ppm}$ is added as a $100 \mathrm{~mL}$ soil drench at biweekly intervals. Postiglione and Fangnano (1995) used EDU to test for effects of ambient ozone on lettuce, subterranean clover, bean and tomato while Fumagalli et al. (1997) used both EDU and open-top chambers to study the effects of ambient ozone on white clover plants in the Milan region of Italy. In both studies researchers found no ozone-related effects of EDU.

In 1992, Kostka-Rick and Manning (1992a) examined the dose response to EDU applied as a soil drench in radish exposed to ozone. They showed that the concentration and dose of EDU could be reduced by 3 to 7 -fold relative to earlier studies without compromising the effectiveness of 
the product. They found that at these dosages plant growth at all stages examined (early to late hypocotyl thickening) was completely preserved in the face of ozone stress although EDU did cause slight leaf margin necrosis and hyponastic leaf deformations. These studies point to the importance of conducting dose response experiments prior to the use of the EDU method in assessments of crop effects. Kostka-Rick and Manning further emphasized this caveat in papers published over the following two years from work on EDU protection of radish and bean (Kostka-Rick and Manning 1993a,b).

\section{Timing of Application}

Clarke et al. (1983) pointed to the importance of the timing of the exposure episode in relation to tuber formation in determining whether EDU could impart beneficial effects. Hofstra et al. (1978) compared the efficacy of EDU to carboxin and benomyl in reducing ozone-related yield losses in navy bean. They found that EDU was the most effective and that the timing of application was critical in eliciting optimal effect. In 1979, McClenahen tested the efficacy of EDU in protecting white ash and black cherry from ozone injury. McClenahen (1979) found that weekly application of EDU to seedling foliage provided near complete protection from ozone at concentrations of up to $300 \mathrm{ppb}$. In 1980 , Weidensaul showed that pinto bean plants were best protected from ozone injury when EDU was applied 3 to 7 days prior to ozone exposure but that EDU afforded no protection to foliage that had not yet formed when the chemical was applied.

\section{Side-effects}

The possible side-effects of EDU were discussed by Legassicke and Ormrod (1981) and Foster et al. (1983) who showed that EDU did not increase yield in the ozone resistant cultivar of tomato 'New Yorker' nor in the 'White Rose' potato, respectively. Similar findings were reported by Clarke et al. (1983) in the potato cultivar 'Green Mountain'. Foster et al. (1983) also showed that EDU applied every 2 weeks did not cause increased yields in ozone-sensitive cultivars of potato grown in ozone-free air. Bisessar and Palmer (1984) used approximately the same rate of application of EDU for tobacco as did Foster et al. but applied it every 7-10 days. Increasing the frequency of application and perhaps over-dosing the plants caused side-effects of EDU on root and shoot biomass. Greenhalgh et al. (1987) used open-top chambers to verify whether EDU had side-effects when it was applied to soybean. They found no differences in plant height, pod number, seed yield, chlorophyll content and foliar injury between soybean plants grown in ozone-free air in the presence or absence of EDU. 


\section{CONCLUSIONS AND RECOMMENDATIONS}

Several studies suggest that the application of certain chemical protectants against ozone might be a reliable means by which to assess crop effects under field conditions.

While many chemicals have been shown to convey partial or total protection against ozone injury, many are ineffective and have unacceptable side-effects rendering them of little value for the purpose of crop effects assessments in the field. This is true of some of the most promising antiozonants. For example, even though the fungicide benomyl has been found to effectively control ozone injury in a number of plants, it would be impossible to separate the fungicidal benefits from its antiozonant properties in the field.

We conclude that EDU is specific in the suppression of ozone injury in a wide variety of plant species. Studies conducted to date have shown that EDU has few side-effects and is effective on almost all plants studied. If appropriate exposure/response and toxicological studies are conducted with EDU and ozone, it should be possible to use EDU for assessing crop effects in the field. Therefore we recommend that the EDU method be adopted for studies aimed at the assessment of crop effects under field conditions in Alberta. EDU at a concentration of $250-$ $500 \mathrm{ppm}$ should be applied to the foliage to runoff every 7 to 10 days throughout the vegetation period. This should allow for the partial or total mitigation of ozone effects in chronic exposures at concentrations of up to $80 \mathrm{ppb}$. For the preliminary determination of the potential use of EDU application in assessing effects of ozone on crops of Alberta, we recommend that studies be conducted at sites where ozone levels are greatest, perhaps Fort Saskatchewan or east Edmonton, with an ozone control site established near Vegreville where ozone levels are very low.

Information on the relative sensitivity of common Alberta crops is lacking, making it difficult to determine which species should be used in these studies. We recommend that at least two species be studied. Based on their relative importance, we recommend that barley (Hordeum vulgare) and canola (Brassica napus - the most common species of canola) be used. 
Adedipe NO and DP Ormrod (1972) Hormonal Regulation of ozone phytotoxicity in Raphanus sativus. Zeitschrift Fuer Pflanzenphysiologie 68: 254-258.

Ainsworth N and MR Ashmore (1992) Assessment of ozone effects on beech by injection of a protectant chemical. Forest Ecology and Management 51: 129-136.

Ainsworth N, I Fumagalli, A Giorcelli, L Mignanego, G Schenone and L Vietto (1996) Assessment of EDU stem injections as a technique to investigate the response of trees to ambient ozone in field conditions. Agriculture, Ecosystems and Environment 59: 33-42.

Astorino G, I Margani and P Tripodo (1995) The response of Phaseolus vulgaris L. cv. Lit. to different dosages of the anti-ozonant ethylenediurea (EDU) in relation to chronic treatment with ozone. Plant Science 111: 237-248.

Ball GR, J Benton, D Palmer-Brown, J Fuhrer, L Skarby, BS Gimeno and G Mills (1998) Identifying factors which modify the effects of ambient ozone on white clover (Trifolium repens) in Europe. Environmental Pollution 103: 7-16.

Bambawale OM (1986) Evidence of ozone injury to a crop in India. Atmospheric Environment 20(7): 1501-1503.

Bennett JH, E H Lee and HH Heggestad (1978) Apparent photosynthesis and leaf stomatal diffusion in EDU treated ozone-sensitive bean plants. Proceedings of the $5^{\text {th }}$ Annual Meeting of the Plant Growth Regulator Working Group 242-246.

Bergweiler CJ and WJ Manning (1999) Inhibition of flowering and reproductive success in spreading dogbane (Apocynum androsaemifolium) by exposure to ambient ozone. Environmental Pollution 105: 333-339.

Bertinuson T, H LeCoultre and WC Waterman (1961) The inhibitory effect of zinc ethylene bisdithiocarbamate dust on weather fleck of Connecticut shade-grown tobacco. Tobacco Science 5: 28-30.

Bialobok S (1984) Controlling atmospheric pollution. Air Pollution and Plant Life (W Treshow ed.) John Wiley \& Sons, New York 451-478.

Bisessar S (1982) Effect of Ozone, Antioxidant Protection, and Early Blight on Potato in the Field. Journal of the American Society of Horticultural Science 107(4): 597-599.

Bisessar S and KT Palmer (1984) Ozone, Antioxidant spray and Meloidogyne hapla effects on tobacco. Atmospheric Environment 18(5): 1025-1027. 1984.

Bors W, C Langebartels, C Michel and H Sandermann Jr. (1989) Polyamines as radical scavengers and protectants against ozone damage. Phytochemistry 28(6): 1585-1595. 
Brennan EG, IA Leone and BB Clarke (1987) EDU: A chemical for evaluating ozone foliar injury and yield reduction on field-grown crops. Journal of Tropical Plant Diseases 5: 3542.

Brennan EG, BB Clarke, B Greenhalgh-Weidman and G Smith (1990) An assessment of the impact of ambient ozone on field-grown crops in New Jersey using the EDU method: Part 2 - Soybean (Glycine max (L.) Merr.). Environmental Pollution 66: 361-373.

Brunschon-Harti S, A Fangmeier and HJ Jager (1995a) Influence of ozone and ethylenediurea (EDU) on growth and yield of bean (Phaseolus vulgaris L.) in open-top field chambers. Environmental Pollution 90(1): 89-94.

Brunschon-Harti S, A Fangmeier and HJ Jager (1995b) Effects of ethylenediurea and ozone on the antioxidative systems in beans (Phaseolus vulgaris L.). Environmental Pollution 90(1): 95-103.

Cannon WN Jr., BR Roberts and JH Barger (1993) Growth and physiological response of waterstressed yellow-poplar seedlings exposed to chronic ozone fumigation and ethylenediurea. Forest Ecology and Management 61: 61-73.

Carnahan JE, EL Jenner and EKW Wat (1978) Prevention of ozone injury to plants by a new protectant chemical. Phytopathology 68: 1225-1229.

Carney AW, GR Stephenson, DP Ormrod and GC Ashton (1973) Ozone-herbicide interactions in crop plants. Weed Science 21: 508-511.

Cathey HM and HE Heggestad (1972) Reduction of ozone damage to Petunia hybrida Vilm. by use of growth regulating chemicals and tolerant cultivars. Journal of the American Society of Horticultural Science 97(6): 695-700.

Cathey HM and HE Heggestad (1973) Effects of growth retardants and fumigations with ozone and sulfur dioxide on growth and flowering of Euphorbia pulcherrima Willd. Journal of the American Society of Horticultural Science 98(1): 3-7.

Cathey HM and HE Heggestad (1978) Reduction of ozone damage to florist and nursery crops by a new protectant chemical, EDU. HortScience 13(3): 57.

Cathey HM and HE Heggestad (1982a) Ozone and sulfur dioxide sensitivity of petunia: Modification by ethylenediurea. Journal of the American Society of Horticultural Science 107(6): 1028.

Cathey HM and HE Heggestad (1982b) Ozone sensitivity of herbaceous plants: Modification by ethylenediurea. Journal of the American Society of Horticultural Science 107(6): 1042.

Cathey HM and HE Heggestad (1982c) Ozone sensitivity of woody plants: Modification by ethylenediurea. Journal of the American Society of Horticultural Science 107(6): 10421045. 
Chanway CP and VC Runeckles (1984) Effect of ethylene diurea (EDU) on ozone tolerance and superoxide dismutase activity in bush bean. Environmental Pollution (Series A) 35: 4956.

Clarke B, M Henninger and E Brennan (1978) The effect of two antioxidants on foliar injury and tuber production in 'Norchip' potato plants exposed to ambient oxidants. Plant Disease Reporter 62(8): 715-717.

Clarke BB, MR Henninger and E Brennan (1983) An assessment of potato losses caused by oxidant air pollution in New Jersey. Phytopathology 73: 104-108.

Clarke BB, E Brennan and J Rebbeck (1984) EDU: A tool for assessing crop loss due to ambient oxidants. Phytopathology 74(7): 843.

Clarke BB, B Greenhalgh-Weidman and EG Brennan (1990) An assessment of the impact of ambient ozone on field-grown crops in New Jersey using the EDU method: Part 1- White potato (Solanum tuberosum). Environmental Pollution 66: 351-360.

Committee on Medical and Biologic Effects of Environmental Pollutants (1977) Ozone and other photochemical oxidants. National Academy of Science. Washington D.C. 437-585.

Curtis LR (1973) Control of ozone injury on white beans with oxathiin analogs. M.Sc. Thesis. The University of Guelph $53 \mathrm{pp}$.

Curtis LR, LV Edgington and G Hofstra (1973) Relationship of ozone injury to time of application of carboxin analogues. Phytopathology 63: 200.

Curtis LR, DA Littlejohns and LV Edgington (1974) Effectiveness of benomyl and oxathiin analogs in reducing bronzing on white beans under field conditions. Phytopathology 64: 579-580.

Curtis LR, LV Edgington and DJ Littlejohns (1975) Oxathiin chemicals for control of bronzing of white beans. Canadian Journal of Plant Science 55: 151-156.

Dass HC and GM Weaver (1968) Modification of ozone damage to Phaseolus vulgaris by antioxydants, thiols and sulfhydryl reagents. Canadian Journal of Plant Science 48: 569574.

Eckardt NA and EJ Pell (1996) Effects of ethylenediurea (EDU) on ozone-induced acceleration of foliar senescence in potato (Solanum tuberosum L.). Environmental Pollution 92(3): 299-306.

Eberhardt J, E Brennan, J Kuser and R Harkov (1988) Ozone tolerance in New Jersey fieldgrown eastern white pine. Journal of Arboriculture 14(8): 185-192.

Elfving DC, MD Gilbert, LJ Edgerton, MH Wilde and DJ Lisk (1976) Antioxidant and antitranspirant protection of apple foliage against ozone injury. Bulletin of Environmental Contamination \& Toxicology 15(3): 336-341. 
Elliot C, J Eberhardt, J Rebbeck and E Brennan (1985) Response of green ash and white ash to ambient rain and ozone pollution in New Brunswick, New Jersey. Proceedings of the Annual Meeting of the Air Pollution Control Association. p.1-2.

Ensing J, G Hofstra and RC Roy (1985) The impact of ozone on peanut exposed in the laboratory and field. Phytopathology 75(4): 429-432.

Fagnano M and A Zoina (1995) Ethylenediurea affect on productivity and phytosanitary status of bean. Agricoltura Mediterranea Special Volume (Proceedings) 119-124.

Fieldhouse DJ (1978) Chemical control of ozone damage on watermelon. HortScience 13(3): 23.

Flagler RB and BG Toups (1992) Use of sodium erythorbate to determine the effects of ambient ozone on shortleaf pine. In: The responses of southern commercial forests to air pollution. (RB Flagler ed.) Air and Waste Management Association, Pittsburgh, PA. 325326.

Flagler RB and JE Lock (1994) Effects of EDU and Ozoban on the growth of shortleaf pine seedlings in the field. Annual Ecological Society of America (ESA) meeting: Science and public policy 66-67.

Flagler RB, JE Lock and CG Elsik (1994) Assessing the response of shortleaf pine to ozone using sodium erythorbate and ethylenediurea. Proceedings of the Air and Waste Management Association Meeting 1-13.

Fletcher RA, NO Adedipe and DP Ormrod (1972) Abscisic acid protects beans leaves from ozone-induced phytotoxity. Canadian Journal of Botany 50: 2389-2391.

Fletcher RA and G Hofstra (1985) Triadimefon a plant multi-protectant. Plant and Cell Physiology 26: 775-780.

Foster KW, JP Guerard, RJ Oshima, JC Bishop and H Timm (1983) Differential ozone susceptibility of centennial russet and white rose potato as demonstrated by fumigation and antioxidant treatments. American Potato Journal 60: 127-139.

Freebairn HT (1960) The prevention of air pollution damage to plants by the use of vitamin C sprays. Journal of Air Pollution Control Association 10(4): 314-317.

Freebairn HT and OC Taylor (1960) Prevention of plant damage from air-borne oxidizing agents. Proceedings of the American Society of Horticultural Science 76: 693-699.

Freebairn HT (1963) Uptake and movement of $\mathrm{C}^{14}$ ascorbic acid in bean plants. Physiologia Plantarum 16: 517-522.

Fukuda M, T Kisaki and A Koiwai (1975a) Studies on weather fleck on tobacco leaves. Screening of chemicals for control of ozone injury to tobacco. Bulletin of the Okayama Tobacco Experiment Station No. 35 (Special Issue No.3). 
Fukuda M, T Kisaki and A Koiwai (1975b) Weather fleck on tobacco leaves. XIX. Screening of chemicals for control of ozone injury to tobacco. Okayama Tabako Shikenjo Hokoku 35: 75-85.

Fumagalli I, L Mignanego and G Violini (1997) Effects of tropospheric ozone on white clover plants exposed in open-top chambers or protected by the antioxidant ethylene-diurea (EDU). Agronomie 17: 271-281.

Gayed SK (1983) The effect of ethylene diurea on weather fleck and on certain properties of the flue-cured tobacco in Ontario. Tobacco International 185: 45-46.

Gilbert MD, GA Maylin, DC Elfving, LJ Edgerton, WH Gutenmann and DJ Lisk (1975) The use of diphenylamine to protect plants against ozone injury. HortScience 10(3): 228-231.

Gilbert MD, DC Elfving and DJ Lisk (1977) Protection of plants against ozone injury using the antiozonant N-(1,3-Dimethylbuty)-N'-Phenyl-p-Phenylenediamine. Bulletin of Environmental Contamination \& Toxicology 18(6): 783-786.

Gillespie C, V Bermejo, F Casula, J Cardosa-Vilhena, S Pearson, J Ollerenshaw and JD Barnes (1998) Mechanisms underlying EDU-Induced ozone resistance. In: Responses of Plant Metabolism to Air Pollution and Global Change. (LJ De Kok and I Stulen eds.) 309-310.

Godzik B (1997) Surface ozone concentration in southern Poland: tobacco cultivar exposure study. Fragmenta Floristica et Geobotanica 42(1): 161-172.

Godzik B and WJ Manning. (1998) Relative effectiveness of ethylenediurea, and constituent amounts of urea and phenylurea in ethylenediurea, in prevention of ozone injury to tobacco. Environmental Pollution 103: 1-6.

Greenhalgh B, E Brennan and T Leone (1987) Evidence in support of the use of EDU to assess ozone-induced plant injury. Phytopathology 77: 1761.

Hassan IA, MR Ashmore and JNB Bell (1995) Effect of ozone on radish and turnip under Egyptian field conditions. Environmental Pollution 89: 107-114.

Heggestad HE (1988) Reduction in soybean seed yields by ozone pollution? APCA Note-Book 38(8): 1040-1041.

Hofstra G, DA Littlejohns and RT Wukasch (1978) The efficacy of the antioxidant ethylenediurea (EDU) compared to carboxin and benomyl in reducing yield losses from ozone in navy bean. Plant Disease Reporter 62(4): 350-352.

Hofstra G, RT Wukasch and DM Drexler (1983) Ozone injury on potato foliage as influenced by the antioxidant EDU and sulphur dioxide. Canadian Journal of Plant Pathology 5: 115119. 
Hucl P and WD Beversdorf (1982) The response of selected Phaseolus vulgaris L. cultivars to ozone under controlled fumigation and ambient field levels. Canadian Journal of Plant Science 62:561-569.

Jones JL (1963) Ozone damage: Protection for plants. Science 140: 1317-1318.

Kender WJ, EF Taschenberg and NJ Shaulis (1973) Benomyl protection of grapevines from air pollution injury. HortScience 8(5): 396-398.

Kendrick JB Jr., JT Middleton and EF Darley (1954) Chemical protection of plants from ozonated olefin (smog) injury. Phytopathology 44: 494-495.

Kendrick JB Jr., EF Darley and JT Middleton (1962) Chemotherapy for oxidant and ozone induced plant damage. International Journal of Air and Water Pollution 6: 391-402.

Kitano H, T Shinohara, Y Yamamoto, T Kimura, A Koiwai, T Kisaki and M. Fukuda (1975) Studies on weather fleck on tobacco leaves. Effects of some protective chemicals for weatherfleck on the production of tobacco leaves. Bulletin of the Okayama Tobacco Experiment Station 35 (Special Issue No.3): 86-95.

Klingaman GL and CB Link (1975) Reduction air pollution injury to foliar of Chrisanthemum morifolium Ramat. using tolerant cultivars and chemical protectants. Journal of the American Society of Horticultural Science 100(2): 173-175.

Knapp CE and DJ Fieldhouse (1970) Alar and folicote sprays for reducing ozone injury on four solanaceous genera. HortScience 5: 338 .

Koiwai A (1977) Studies on the protective chemicals against ozone injury to tobacco leaves. Bulletin of the Okayama Tobacco Experiment Station 38: 1-58.

Koiwai A, H Kitano, M Fukuda and T Kisaki (1974) Methylenedioxyphenyl and its related compounds as protectants against ozone injury to plants. Agricultural and Biological Chemistry 38(2): 301-307.

Koiwai A and K Hiroshi (1975) Studies on weather fleck on tobacco leaves. Effects of some protective chemicals for weather fleck on the production of tobacco leaves. Bulletin of the Okayama Tobacco Experiment Station 35 (Special Issue No.3).

Koiwai A and T Kisaki (1976) Effect of ozone on photosystem II of tobacco chloroplasts in the presence of piperonyl butoxide. Plant \& Cell Physiology 17: 1199-1207.

Koiwai A, M Fukuda and T Kisaki (1977) Effect of piperonyl butoxide and diphenylamine on lipid peroxidation in ozonated chloroplasts. Plant Cell Physiology 18: 127-139.

Kostka-Rick R and WJ Manning (1992a) Effects and interactions of ozone and the anti-ozonant EDU at different stages of radish (Raphanus sativus L.) development. Journal of Experimental Botany 43(257): 1621-1631. 
Kostka-Rick R and WJ Manning (1992b) Partitioning of biomass and carbohydrates in fieldgrown radish under ambient concentrations of ozone, and treated with the anti-ozonant ethylene-diurea (EDU). New Phytologist 121: 187-200.

Kostka-Rick R and WJ Manning (1993a) Dynamics of growth and biomass partitioning in fieldgrown bush bean (Phaseolus vulgaris L.) treated with the antiozonant ethylenediurea (EDU). Agriculture, Ecosystems and Environment 47: 195-214.

Kostka-Rick R and WJ Manning (1993b) Dose-response studies with ethylenediurea (EDU) and radish. Environmental Pollution 79: 249-260.

Kostka-Rick R and WJ Manning (1993c) Dose-response studies with the antiozonant ethylenediurea (EDU), applied as a soil drench to two growth substrates, on greenhousegrown varieties of Phaseolus vulgaris L. Environmental Pollution 82: 63-72. 1993.

Kostka-Rick R, WJ Manning and-JP Buonaccorsi (1993) Dynamics of biomass partitioning in field-grown radish varieties, treated with ethylenediurea. Environmental Pollution 80: 133-145.

Kuehler EA and RB Flagler (1999) The effects of sodium erythorbate and ethylenediurea on photosynthetic function of ozone-exposed loblolly pine seedlings. Environmental Pollution 105: 25-35.

Laguette RHD, LI de Bauer, SJ Kohashi and MN Marban (1987) Impact of environmental oxidants on the bean crop in Montecillos state of Mexico. Agrociencia 66: 83-95.

Larkin RC (1973) Reduction of ozone damage on bean and tobacco with peroxidase injections. M.Sc. Thesis, Newark: University of Delaware 19 pp.

Lee EH (1995) Antioxidant Mechanism(s) of Ethylenediurea and ozone protection: Reexamination of free radical scavenger systems in snapbean exposed to Ozone. Plant Physiology 108(Suppl2): 81.

Lee EH, RA Rowland and CL Mulchi (1990) Growth regulators serve as a research tool to study the mechanism of plant response to air pollution stimuli. British Society for Plant Growth Regulation, Monograph 20: 127-137.

Lee EH, GF Kramer, RA Rowland and M Agrawal (1992) Antioxidants and growth regulators counter the effects of $\mathrm{O}_{3}$ and $\mathrm{SO}_{2}$ in crop plants. Agriculture, Ecosystems and Environment 38: 99-106.

Lee EH, A Upadhyaya, M Agrawal and RA Rowland (1997) Mechanisms of ethylenediurea (EDU) induced ozone protection: Reexamination of free radical scavenger systems in snap bean exposed to $\mathrm{O}_{3}$. Environmental and Experimental Botany 38: 199-209.

Legassicke BC and DP Ormrod (1981) Suppression of ozone-injury on tomatoes by ethylene diurea in controlled environments and in the field. HortScience 16(2): 183-184. 
Lisk DJ (1975) Protecting plants against injury from air pollution. New York's Food and Life Sciences 8(4): 3-5.

Littlejohns D, AD McLaren and JW Ayleswort (1976) The effect of foliar sprays in controlling ozone damage in white beans. Canadian Journal of Plant Science 56: 430.

Long RP and DD Davis (1991) Black cherry growth response to ambient ozone and EDU. Environmental Pollution 70: 241-254.

Lorenzini G, L Guidi and A Panattoni (1987) Evaluation of fungicide effects on ozone injury to tobacco plants. Annual Review of Applied Biology 110(Suppl): 102-103.

Macher F and MR Wasescha (1995) Damage by ozone and protection by ascorbic acid in barley leaves. Journal of Plant Physiology 147: 469-473.

Manning WJ (1988) EDU: A research tool for assessment of the effects of ozone on vegetation. Proceedings of the $81^{\text {st }}$ Air Pollution Control Association Annual Meeting Paper No. 8869.2: 2-8.

Manning WJ (1992) Assessing the effects of ozone on plants: Use and misuse of ethylenediurea (EDU). Proceedings of the $85^{\text {th }}$ Annual Meeting and Exhibition on Air and Waste Management Association $11 \mathrm{pp}$.

Manning WJ (1995) Use of protective chemicals to assess the effects of ambient ozone on vegetation. Proceedings of the $88^{\text {th }}$ Annual Meeting of the Air \& Waste Management Association $12 \mathrm{pp}$.

Manning WJ, WA Feder and PM Papia (1972) Influence of long-term low levels of ozone and benomyl on growth and nodulation of pinto bean plants. Phytopathology 62(5): 497.

Manning WJ and PM Papia (1972) Influence of long-term low levels of ozone on the leaf surface mycoflora of pinto bean plants. Phytopathology 62(5): 497.

Manning WJ and PM Vardaro (1973a) Suppression of oxidant injury on beans by systemic fungicides. Phytopathology 63: 1415-1416.

Manning WJ and PM Vardaro (1973b) Suppression of oxidant air pollution injury on bean plants by systemic fungicides under field conditions. Phytopathology 63: 204.

Manning WJ, WA Feder and PM Vardaro (1973a) Reduction of chronic ozone injury on poinsettia by benomyl. Canadian Journal of Plant Science 53: 833-835.

Manning WJ, WA Feder and PM Vardaro (1973b) Benomyl in soil and response of pinto bean plants to repeated exposures to a low level of ozone. Phytopathology 63: 1539-1540.

Manning WJ, WA Feder and PM Vardaro (1973c) Suppression of oxidant injury by benomyl: Effects on yields of bean cultivars in the field. Journal of Environmental Quality 3(1): 13. 
Manning WJ, WA Feder and PM Vardaro (1974) Suppression of oxidant injury by benomyl: Effects on yields of bean cultivars in the field. Journal of Environmental Quality 3(1): 13.

Manning WJ and SV Krupa (1992) Experimental methodology for studying the effects of ozone on crops and trees. In: Surface level ozone exposures and their effects on vegetation. (AS Lefohn ed.) p.93-156.

McClenahen JR (1979) Effects of ethylene diurea and ozone on the growth of tree seedlings. Plant Disease Reporter 63(4): 320-323.

Middleton JT, JB Kendrick Jr. and EF Darley (1953) Olefinic peroxide injury to bean as influenced by age, variety, chemical additions and toxicant dosage. Phytopathology 43: 588.

Miller PM and GS Taylor (1970) - Effects of several nematicides and benomyl on the incidence of weather fleck of tobacco. Plant Disease Reporter 54(8): 672-674.

Miller PM, H Tomlinson and GS Taylor (1976) Reducing severity of ozone damage to tobacco and beans by combining benomyl or carboxin with contact nematicides. Plant Disease Reporter 60: 433-436.

Miller JE, WA Pursley and AS Heagle (1994) Atmospheric pollutants and trace gases. Effects of ethylenediurea on snap bean at a range of ozone concentrations. Journal of Environmental Quality 23: 1082-1089.

Moyer J, H Cole Jr. and NL Lacasse (1974a) Reduction of ozone injury on Poa annua by benomyl and thiophanate. Plant Disease Reporter 58(1): 41-44.

Moyer J, H Cole Jr. and NL Lacasse (1974b) Suppression of naturally occurring oxidant injury on azalea plants by drench or foliar spray treatment with benzimidazole or oxathiin compounds. Plant Disease Reporter 58(2): 136-138.

Moyer JW and SH Smith (1995) Oxidant injury reduction on tobacco induced by tobacco etch virus infection. Environmental Pollution 9: 103-106.

Musselman RC (1985) Protecting grapevines from ozone injury with ethylenediurea and benomyl. American Journal of Enology and Viticulture 36(1): 38-42.

Musselman RC, WJ Kender, WM Hertzberg and RE Melious (1978) Effectiveness of EDU as an anti-oxidant for grapevines. HortScience 13(3): 57.

Musselman RC and BA Hale (1997) Methods for controlled and field ozone exposures of forest tree species in North America. In: Forest decline and ozone. A Comparison of controlled chamber and field experiments (Sandermann, Welburn and Heath eds.) Springer-Verlag, New York pp. 296-315. 
Ommen OE, J Bender and HJ Weigel (1994) Effects of ozone on white clover: Protection of ozone damage by ethylenediurea. Angewandte Botanika 68: 146-150.

Ormrod DP and NO Adedipe (1974) Protecting horticultural plants from atmospheric pollutants: A Review. HortScience 9(2): 108-111.

Ormrod DP and DW Beckerson (1986) Polyamines as antiozonants for tomato. HortScience 21(4): 1070-1071.

Papple DJ and DP Ormrod (1977) Comparative efficacy of ozone-injury suppression by benomyl and carboxin on turfgrass. Journal of the American Society of Horticultural Science 102: 792-796.

Pandey J and M Agrawal (1993) Protection of plants against air pollutants: Role of chemical protectants. Journal of Environmental Management 37: 163-174.

Pearson RG and KE Percy (1997) Establishment of a Canadian air quality objective for ozone based on vegetation effects. Vegetation Objective Working Group report to the Canadian Environmental Act/Federal-Provincial Advisory Committee's Working Group on Air Quality Objectives and Guidelines $172 \mathrm{pp}$.

Pell EJ (1976) Influence of benomyl soil treatment on pinto bean plants exposed to peroxyacetyl and ozone. Phytopathology 66: 731-733.

Pellissier M (1971) Effect of foliar and root treatments of benomyl in reducing ozone injury to pinto bean and cucumber. (Center for Air Environment Studies Publ. 213-7) M.Sc. Thesis. University Park: Pennsylvania State University 49.

Pellissier M, NL Lacasse and H Cole (1971a) Effect of benomyl on the response to ozone in pinto beans. Phytopathology 64: 131-132.

Pellissier M, NL Lacasse and H Cole Jr. (1971b) Effectiveness of benzimidazole and two benzimidazole derivative fungicides in reducing ozone injury to Phaseolus vulgaris 'Pinto 111'. Phytopathology 61: 906.

Pellissier M, NL Lacasse and H Cole Jr. (1972a) Effectiveness of benzimidazole, benomyl, and thiabendazole in reducing ozone injury to pinto beans. Phytopathology 62: 580-582.

Pellissier M, NL Lacasse and H Cole Jr. (1972b) Effectiveness of benomyl and benomylfolicote treatments in reducing ozone injury to pinto beans. Journal of the Air Pollution Control Association 22(9): 722-724.

Pihl G, PE Karlsson, G Sellden, L Skarby and H Pleijeil (1995) Clover as an indicator plant for phytotoxic ozone concentrations: visible injury in relation to species, leaf age and exposure dynamics. New Phytologist 129: 355-365.

Pitcher LH, E Brennan and BA Zilinskas (1992) The antiozonant ethylenediurea does not act via superoxide dismutase induction in bean. Plant Physiology 99: 1388-1392. 
Pleijel H, A Norberg, G Sellden and L Skarby (1999) Tropospheric ozone decreases biomass production in radish plants (Raphanus sativus) grown in rural south-west Sweden. Environmental Pollution 106: 143-147.

Postiglioni L and M Fagnano (1995) Ozone injury and ethylenediurea: first results on different species in the Campania region. Agricoltura Mediterranea Special Volume (Proceedings) 109-118.

Proctor JTA (1978) Cultivar sensitivity, growth, yield and protection of cucumber exposed to ozone. HortScience 13(3): 57.

Ranieri A and GF Soldatini (1995) Detoxificant systems in bean plants grown in polluted air: effects of the antioxidant EDU. Agricoltura Mediterranea 125: 375-386.

Regner-Joosten K, R Manderscheid, E Bergmann, M Bahadir and HJ Weigel (1994) An HPLC method to study the uptake and partitioning of the antiozonant EDU in bean plants. Angewandte Botanik 68: 151-155.

Reilly JJ and LD Moore (1982) Influence of selected herbicides on ozone injury in tobacco (Nicotiana tabacum). Weed Science 30: 260-263.

Reinert RA and HW Spurr Jr. (1972) Differential effect of fungicides on ozone injury and brown spot disease of tobacco. Journal of Environmental Quality 1(4): 450-452.

Rich S (1964) Ozone damage to plants. Annual Review of Phytopathology 2: 253-266.

Rich S, R Ames and JW Zukel (1974) 1,4-oxathiin derivatives protect plants against ozone. Plant Disease Reporter 58(2): 162-164.

Rich S and GS Taylor (1960) Antiozonants to protect plants from ozone damage. Science 132: 150-151.

Roberts BR and KF Jensen (1985) Modification of ozone sensitivity in seedlings by ethylenediurea: Soil application vs. stem injection. Journal of the American Society of Horticultural Science 110(2): 178-180

Roberts BR (1987) Photosynthetic response of yellow poplar seedlings to the antioxidant chemical ethylenediurea. Journal of Arboriculture 13: 154.

Roberts BR, LR Wilson, JJ Cascino and GP Smith (1987) Autoradiographic studies of ethylenediurea distribution in woody plants. Environmental Pollution 45: 81-86.

Ross DN, RA Reinert and RG Halfacre (1976) The response of Chrysanthemum morifolium to chronic exposure to ozone and suppression of injury by ancymidol. HortScience 11(3): 10. 
Rubin B, JRC Leavitt, D Penner and AW Saettler (1980) Interaction of antioxidants with ozone and herbicide stress. Bulletin of Environmental Contamination and Toxicology 25: 623629.

Rufner, R FH Whitham and H Cole Jr. (1975) Ultrastructure of chloroplasts of Phaseolus vulgaris leaves treated with benomyl and ozone. Phytopathology 65: 345-349.

Runeckles VC and HM Resh (1975) Effects of cytokinins on responses of bean leaves to chronic ozone treatment. Atmospheric Environment 9: 749-753.

Saettler AW (1981) Yield response of navy bean treated with the antioxidant chemical ethylenediurea. Research Report. Michigan State University Agricultural Research Station. \#427, 3-7.

Salam MA and G Soja (1997) Investigation of the air pollutant effects on some agricultural crops and grass plants in Seibersdorf and ethylene diurea (EDU) as antiozonant. International Congress of Acid Snow and Rain 474-490.

Schenone G, I Fumagalli, L Mignanego and G Violoni (1995) Effects of ambient ozone on bean (Phaselous vulgaris L.): Results of an experiment with the antioxidant EDU in the Po Plain (Italy) in the 1993 season. Agricoltura Mediterranea Special Volume (Proceedings) 104-108.

Seem RC (1972) Evaluation of the potential chemical protectants from ozone damage to Phaseolus vulgaris L. M.Sc. Thesis. The Pennsylvania State University 69 pp.

Seem RC, H Cole Jr. and NL Lacasse (1972) Suppression of ozone injury to Phaseolus vulgaris 'Pinto III' with triarimol and its monochlorophenyl cyclohexyl analogue. Plant Disease Reporter 56(5): 386-390.

Seem RC, H Cole Jr. and NL Lacasse (1973) Suppression of Ozone Injury to Phaseolus vulgaris L. with Thiophanate Ethyl and its Methyl Analogue. Journal of Environmental Quality 2(2): 266-268.

Seidman G, IJ Hindawi and WW Heck (1965) Environmental conditions Affecting the use of plants as indicators of air pollution. Journal of the Air Pollution Control Association 15(4): $168-170$.

Siegel SM (1962) Protection of plants against airborne oxidants: Cucumber seedlings at extreme ozone levels. Plant Physiology 37: 261-266.

Silber G (1964) Effectiveness of some chemicals for the prevention of weather fleck of fieldgrown tobacco. Tobacco Science 8: 93-95.

Smith G, B Greenhalgh, E Brennan and J Justin (1987) Soybean yield in New Jersey relative to ozone pollution and antioxidant application. Plant Disease Reporter 71: 121-125. 
Sung SSJ and LD Moore (1979) The influence of three herbicides on the sensitivity of greenhouse-grown flue-cured tobacco (Nicotiana tabacum) plants to ozone. Weed Science 27(2): 167-173.

Taylor GS (1970) Tobacco protected against fleck by benomyl and other fungicides. Phytopathology 60: 578.

Taylor GS and S Rich (1961) Tobacco fleck controlled with antiozonants. Phytopathology 51: 579-581.

Taylor GS and S Rich (1962) Antiozonant-treated cloth protects tobacco from fleck. Science 135: 928.

Taylor GS and S Rich (1974) Ozone injury to tobacco in the field influenced by soil treatment with benomyl and carboxin. Phytopathology 64:814-817.

Teso RT, RJ Oshima and MI Carmean (1979) Ozone-pesticide interactions. California Agriculture 33: 13-15.

Tiedemann AV (1995) Detection of ozone damage on agricultural crops in Germany using antioxidants. AWMA 88 ${ }^{\text {th }}$ Annual Meeting 95: 10pp.

Toivonen PMA, G Hofstra and RT Wukasch (1982) Assessment of yield losses in white bean due to ozone using the antioxidant EDU. Canadian Journal of Plant Pathology 4: 381386.

Tomlinson H and S Rich (1973a) Anti-senescent compounds reduce injury and steroid changes in ozonated leaves and their chloroplasts. Phytopathology 63: 903-906.

Tomlinson H and S Rich (1973b) Relating ozone resistance to antisenescence in beans treated with benzimidazole. Phytopathology 63: 208.

Tomlinson H and S Rich (1974) Ozone injury and senescence of bean leaves inhibited by phenylurea. Northeastern Abstracts 64.

Tonneijck AEG and CJ van Dijk (1996) Effect of ozone on plants in south Holland. Biomonitoring program 1995. Rapport - DLO-Instituut voor Abrobiologisch en Bodemvruchtbaarheidsonderzoek \#56 23 pp.

Tonneijck AEG and CJ van Dijk (1997a) Effects of ambient ozone on injury and yield of Phaseolus vulgaris at four rural sites in the Netherlands as assessed by using ethylenediurea (EDU). New Phytologist 135: 93-100.

Tonneijck AEG and CJ van Dijk (1997b) Assessing effects of ambient ozone on injury and growth of Trifolium subterraneum at four rural sites in the Netherlands with ethylenediurea (EDU). Agriculture, Ecosystems and Environment 65: 79-88. 
Toshikiyo S, H Kitano and M Fukuda (1976) Effects of inhibitors of photosynthesis on the ozone injury to tobacco plants. Bulletin of the Okayama Tobacco Experiment Station No. 36. 83-86.

Valenti V, R Gianella, L Ederli, S Pasqualini and P Batini (1994) Ozone effects on Nicotiana tabacum photosynthesis. Inhibition of enzymes involved in carbon dioxide fixation. Agricoltura Mediterranea Special Volume (Proceedings) 55-62.

Vandermeiren K, L De Temmerman and N Hookham (1995) Ozone sensitivity of Phaseolus vulgaris in relation to cultivar differences, growth stage and growing conditions. Water, Air and Soil Pollution 85: 1455-1460.

Varshney CK and C Rout (1998) Ethylene diurea (EDU) protection against ozone injury in tomato plants at Delhi. Bulletin of Environmental Contamination and Toxicology 61: 188-193.

Vasiloff GN and DB Drummond (1974) The effectiveness of road dust as a protective agent on buckwheat and pinto bean against sulfur dioxide and ozone. Phytopathology 64: 588.

Walker EK (1961) Chemical control of weather fleck in flue-cured tobacco. Plant Disease Reporter 45(8): 583-586.

Walker EK (1966) Effect of foliar sprays of phygon XL-50 on green fixation in flue-cured tobacco. Canadian Journal of Plant Science 46: 326-328.

Walker EK (1967) Evaluation of foliar sprays for control of weather fleck on flue-cured tobacco. Canadian Journal of Plant Science 47: 99-108.

Walker JT and JC Barlow (1974) Response of indicator plants to ozone levels in Georgia. Phytopathology 64: 1122-1127.

Walker JT and J Melin. (1978) Response of soybean to antioxidant sprays at ambient ozone levels in Georgia. Plant Disease Reporter 62(5): 400-404.

Weidensaul CT (1980) N-[2-(2-oxo-1-imidazolidinyl) ethyl]-N'-phenylurea as protectant against ozone injury to laboratory fumigated pinto bean plants. Phytopathology 70: 42-45.

Whitaker BD, EH Lee and RA Rowland (1990) EDU and ozone protection: Foliar glycerolipids and steryl lipids in snapbean exposed to $\mathrm{O}_{3}$. Physiologia Plantarum 80: 286-293.

Zilinskas BA, B Greenhalgh-Weidman and E Brennan (1990) The relationship between EDU pre-treatment and $\mathrm{C}_{2} \mathrm{H}_{4}$ evolution in ozonated pea plants. Environmental Pollution 65: 241-249. 


National Library of Canada
Bibliothèque nationale du Canada

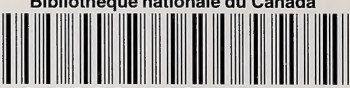

33286520937646 